\title{
An increase in serial sarcomere number induced via weighted downhill running improves work loop performance in the rat soleus
}

Avery Hinks $^{1}$, Kaitlyn Jacob ${ }^{1}$, Parastoo Mashouri ${ }^{1}$, Kyle D. Medak ${ }^{1}$, Martino V. Franchi ${ }^{2}$, David C. Wright ${ }^{1}$, Stephen H. M. Brown ${ }^{1}$, \& Geoffrey A. Power ${ }^{1}$

1 Department of Human Health and Nutritional Sciences, College of Biological Sciences, University of Guelph, 50 Stone Road East, Guelph, Ontario, Canada

2 Department of Biomedical Sciences, Neuromuscular Physiology Laboratory, University of 13 Padua, Padua, Italy.

\section{Research Article}

\section{Correspondence}

20 Geoffrey A. Power PhD.

21 Neuromechanical Performance Research Laboratory

22 Department of Human Health and Nutritional Sciences

23 College of Biological Sciences

24 University of Guelph, Ontario, Canada

25 Telephone: 1-519-824-4120 x53752

26 Email: gapower@uoguelph.ca 


\section{Abstract}

Increased serial sarcomere number (SSN) has been observed in rats via downhill running

31 training due to the emphasis on active lengthening contractions; however, little is known about the

32 influence on dynamic contractile function. Therefore, we employed 4 weeks of weighted downhill

33 running training in rats, then assessed soleus SSN and work loop performance. We hypothesized

34 trained rats would produce greater net work output during faster, higher-strain work loops due to

35 a greater SSN. Thirty-one Sprague-Dawley rats were assigned to a control or training group.

36 Weight was added during downhill running via a custom-made vest, progressing from 5-15\% body

37 mass. Following sacrifice, the soleus was dissected, and a force-length relationship was

38 constructed. Work loops (active shortening followed by passive lengthening) were then performed

39 about optimal muscle length $\left(\mathrm{L}_{0}\right)$ at 1.5-3-Hz cycle frequencies and 1-7-mm strains to assess net

40 work output. Muscles were then fixed in formalin at Lo. Fascicle lengths and sarcomere lengths

41 were measured and used to calculate SSN. Intramuscular collagen content and crosslinking were

42 quantified via a hydroxyproline content and pepsin-solubility assay. Trained rats had longer

43 fascicle lengths $(+13 \%)$, greater $\operatorname{SSN}(+8 \%)$, greater specific active forces $(+50 \%)$, and lower

44 passive forces $(-45-62 \%)$ than controls $(\mathrm{P}<0.05)$. There were no differences in collagen

45 parameters $(\mathrm{P}>0.05)$. Net work output was greater $(+101-424 \%)$ in trained than control rats for

46 the $1.5-\mathrm{Hz}$ loops at 1,3 , and $5-\mathrm{mm}$ strains $(P<0.05)$ and showed relationships with fascicle length

$47 \quad\left(\mathrm{R}^{2}=0.14-0.24, P<0.05\right)$. These results suggest training-induced longitudinal muscle growth may

48 improve dynamic performance. 


\section{Introduction}

Skeletal muscle remodels and adapts in response to specific conditions, as observed across

52 the hierarchy of muscle structural organization (Gans and Bock, 1965; Gans and de Vree, 1987;

53 Jorgenson et al., 2020). An example is longitudinal skeletal muscle growth, seen as muscle fascicle

54 elongation and a corresponding increase in serial sarcomere number (SSN), termed

55 sarcomerogenesis, following downhill running training due to the emphasis on active lengthening

56 (eccentric) contractions (Butterfield et al., 2005a; Chen et al., 2020; Lynn et al., 1998). During

57 unaccustomed eccentric exercise, sarcomeres are overstretched, resulting in suboptimal actin-

myosin overlap. The most supported hypothesis for sarcomerogenesis following eccentric training

59 is that an increase in SSN occurs to re-establish optimal crossbridge overlap regions (Butterfield

60 et al., 2005a; Herring et al., 1984). While the influence of increased SSN on isometric contractile

61 function is well-established (Lynn et al., 1998; Williams and Goldspink, 1978), less is known

62 about the impact on measures of dynamic contractile function.

A physiologically relevant assessment of dynamic performance in vitro is the 'work loop':

64 sinusoidal cycles of muscle shortening and lengthening with phasic bursts of stimulation meant to

65 simulate locomotion (Josephson and Stokes, 1989; Schaeffer and Lindstedt, 2013). Work loops

66 can incorporate a range of cycle frequencies (i.e., speeds of shortening/lengthening) and strains

67 (i.e., muscle length changes), and are therefore influenced by force-velocity and force-length

68 properties of muscle (Josephson, 1999). Hence, there are optimal strains and cycle frequencies for

69 work loop performance, wherein active tension is as high as possible during shortening and as low

70 as possible during subsequent lengthening (i.e., generates greater net work output) (Josephson and

71 Stokes, 1989; Swoap et al., 1997). Sarcomerogenesis may result in placing sarcomeres closer to

72 optimal length throughout the range of motion (especially at longer muscle lengths), thus allowing 
73 individual sarcomeres to shorten slower, optimizing force production across a wider range of

74 muscle lengths based on the force-length and force-velocity relationships (Akagi et al., 2020;

75 Drazan et al., 2019). SSN is also proportional to maximum shortening velocity (Wickiewicz et

76 al., 1984). Taken together, sarcomerogenesis may improve work loop performance particularly in

77 cycles with longer strains and faster cycle frequencies.

78 Contrary to the above hypothesis, Cox et al. (2000) increased SSN of the rabbit latissimus

79 dorsi via 3 weeks of incremental surgical stretch and observed a decrease in maximum work loop

80 power output compared to controls. They attributed this impaired work loop performance despite

81 increased SSN to increased intramuscular collagen content caused by the surgical stretch.

82 Increased collagen content and crosslinking enhance muscle passive stiffness (Brashear et al.,

83 2020; Huijing, 1999; Kjær, 2004; Turrina et al., 2013), which can increase the work of passive

84 lengthening and thereby decrease net work output. While collagen content and mRNAs and

85 growth factors related to collagen synthesis can increase in the rat medial gastrocnemius and

86 quadriceps femoris following isometric, concentric, and eccentric-based training (Han et al., 1999;

87 Heinemeier et al., 2007; Zimmerman et al., 1993), collagen content and key enzymes related to

88 collagen synthesis do not change in the rat soleus following short-term downhill running (Han et

89 al., 1999) or long-term running training (Zimmerman et al., 1993). Collagen crosslinking was also

90 shown to not change in the rat soleus with long-term running training (Zimmerman et al., 1993).

91 Hence, the rat soleus in downhill running training may be a good model to assess the influence of

92 sarcomerogenesis on work loop performance in the absence of increased collagen content.

Previous studies have employed downhill running in rodents with primarily an endurance

94 training stimulus: on consecutive days with no progressive weighted overload (Butterfield et al.,

95 2005a; Chen et al., 2020). A stronger stimulus provided by progressively loaded training may 
96 have a more pronounced impact on muscle architecture and mechanical function (Butterfield and

97 Herzog, 2006; Farup et al., 2012). Furthermore, running on many consecutive days may minimize

98 time for recovery and hence remodelling between exercise bouts (Hyldahl and Hubal, 2014). This

99 distinction in training stimuli was offered previously as explanation for observations of only small

100 adaptations in rat soleus SSN and mechanical function following downhill running training (Chen

101 et al., 2020). Larger magnitude changes in muscle architecture and strength in animals following

1023 days/week training programs support this perspective as well (Butterfield and Herzog, 2006;

103 Ochi et al., 2007; Zhu et al., 2021).

To enhance the effect of downhill running training on muscle architecture, the present

105 study employed downhill running 3 days/week and progressively increased the eccentric stimulus

106 during running via a novel model incorporating weighted vests. The purposes were to: 1) assess

107 how soleus SSN and intramuscular collagen adapt to eccentric training; and 2) investigate the

108 influence on work loop performance. We hypothesized that soleus SSN would increase, and 109 collagen content would not change following training. We also hypothesized that, due to training-

110 induced sarcomerogenesis, work loop performance would improve, particularly in work loops with

111 longer strains and faster cycle frequencies.

112 


\section{Methods}

114 Animals. Thirty-one male Sprague-Dawley rats (sacrificial age $\sim 18$ weeks) were obtained

115 (Charles River Laboratories, Senneville, QC, Canada) with approval from the University of

116 Guelph's Animal Care Committee and all protocols following CCAC guidelines. Rats were

117 housed at $23^{\circ} \mathrm{C}$ in groups of three and given ad-libitum access to a Teklad global $18 \%$ protein

118 rodent diet (Envigo, Huntington, Cambs., UK) and room-temperature water. After a week of

119 acclimation to housing conditions and familiarization with the vests and treadmills, rats were

120 assigned to 1 of 2 groups: control $(n=18)$ or training $(n=13)$. Training consisted of 4 weeks of

121 weighted downhill running 3 days/week. Approximately 72 hours following recovery from the

122 final training day, rats were sacrificed via $\mathrm{CO}_{2}$ asphyxiation and cervical dislocation (Chen et al.,

123 2020). We then immediately dissected the soleus and proceeded with mechanical testing. The

124 soleus was chosen for this study due to its simple fusiform structure with fascicles running tendon

125 to tendon (Williams and Goldspink, 1973), its expected lack of changes in collagen content and

126 crosslinking (Han et al., 1999; Zimmerman et al., 1993), and its suitability for prolonged work

127 loop experiments, being a primarily slow-fibered muscle (Caiozzo and Baldwin, 1997; Swoap et

128 al., 1997). Due to measurement errors in characterizing the force-length relationship after

129 determining Lo, 2 rats (1 control, 1 training) were excluded from analysis of the force-length

130 relationship. Similarly, due to a faulty setup of work loop protocols, the same 2 rats plus 1 other

131 (2 control, 1 training) were excluded from work loop data analysis.

$132 \quad$ Weighted vests. After extensive piloting, we designed a custom-made weighted rodent vest

133 that is both well tolerated by the rat and sufficiently adds weight during running (Figure 1). A

134 child-sized sock was cut into the shape of a vest: the end of the sock was cut off such that the ankle

135 end went around the rat's neck and the toe end went around the rat's torso, then arm holes were 
cut on each side just distal to the neck hole. A T-shaped piece of foam paper was then super-glued

137 on the back of the vest starting above the arm holes. A piece of Velcro was then placed across the

138 wider section of the T-shaped foam paper. The apparatus for holding the weights was then

139 constructed. A strip of packing tape was cut to be the same length as the wider section of the T-

140 shaped foam paper. To allow for easier manipulation of the weight apparatus, a pipe cleaner of

141 the same length was then cut and stuck across the midline of the tape, then a thinner piece of tape

142 was placed over top to hold the pipe cleaner in place. Two $2 \mathrm{~cm} \times 2 \mathrm{~cm}$ Ziplock bags were then

143 stuck on the strip of tape over top of the pipe cleaner, equidistant from the middle. Additional

144 small strips of tape were added as needed to secure these bags in place. A connecting piece of

145 Velcro was then placed on the side of the tape opposite the bags, allowing it to be fastened to the

146 T-shaped foam paper. The appropriate weights (various sizes of coins) were placed in the Ziplock

147 bags. The bags were small enough to hold the coins securely in place, such that they did not move

148 around as the rat ran.

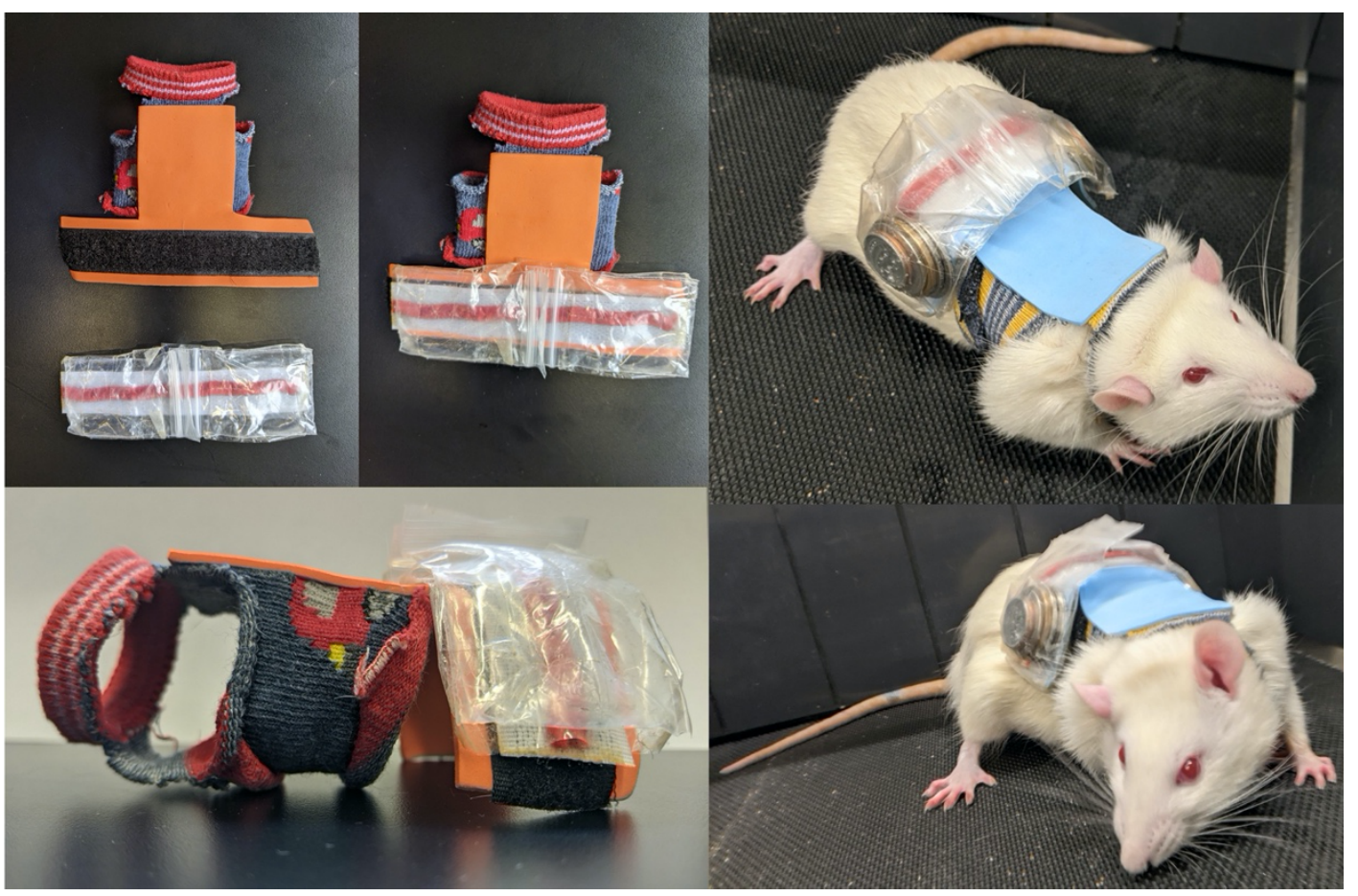


Figure 1: Rat weighted vest design (left) and a rat wearing a vest containing $15 \%$ of its body mass at week 4 of training (right).

Training program. The training program was modelled after those by Butterfield et al. (2005) and Chen et al. (2020), who saw SSN adaptations following 2-4 weeks of downhill running training in the rat vastus intermedius and soleus, respectively, compared to control and uphill running groups. Two weeks prior to training, rats were handled for 1 hour on 3 consecutive days to reduce their stress levels when later applying the vests. The next week (i.e., 1 week before training), the rats underwent 5 consecutive days of familiarization sessions on the treadmill, each consisting of three 3 -minute sets at a $0^{\circ}$ grade and $10-12 \mathrm{~m} / \mathrm{min}$ speed, with 2 minutes of rest between each set. In the first two familiarization sessions they did not wear vests, in the third session they wore an unweighted vest for $1 / 3$ sets, in the fourth session they wore an unweighted

161 vest for $2 / 3$ sets, and in the fifth session they wore an unweighted vest for all 3 sets. Rats who

162 were not compliant to the treadmill after 3 days of attempted familiarization were made controls 163 instead. muscle architectural adaptations with lower compared to higher training frequencies (Butterfield and Herzog, 2006; Morais et al., 2020; Ochi et al., 2007; Wong and Booth, 1988; Zhu et al., 2021), so rats ran 3 days per week (Monday, Wednesday, and Friday). Rats ran on an EXER 3/6 animal 168 treadmill (Columbus Instruments, Columbus, OH, USA) set to a $15^{\circ}$ decline. Rats ran in 5-minute 169 bouts, separated by 2 minutes of rest. They completed 3 bouts on the first day and increased by 2 170 bouts/day up to the 7-bout target (35 minutes total) on the third day of training, which persisted 171 for the remainder of the training period. Rats began each training session at a speed of $10 \mathrm{~m} / \mathrm{min}$, 172 which was increased by $1 \mathrm{~m} / \mathrm{min}$ up to the $16 \mathrm{~m} / \mathrm{min}$ target (Chen et al., 2020). Progressive loading 173 was employed by adding weight equivalent to $5 \%$ of the rat's body mass during the first week, 
$17410 \%$ in the second week, $15 \%$ in the third week, and $15 \%$ readjusted to the new body mass in the

175 fourth week. The training efficacy and safety of this approach was modelled after a weighted vest

176 training review which reported added weights of 5\%-20\% body mass (Macadam et al., 2019), and

177 work by Schilder et al.( 2011), who added up to $36 \%$ of body mass to rats via backpacks to simulate

178 obesity. $15 \%$ of body mass was the maximum weight used in the present study because during

179 piloting we found that adding $20 \%$ of body mass was too cumbersome for the animals while

180 running. Each training session took place at approximately the same time of day (between 9 and

18111 AM).

Experimental setup. Immediately following sacrifice, the soleus was carefully harvested

183 from the right hindlimb (Ma and Irving, 2019). Silk-braided sutures (USP 2-0, metric 3) were tied

184 along the musculotendinous junctions and mounted to the force transducer and length controller

185 in the 806D Rat Apparatus (Aurora Scientific, Aurora, ON, Canada). The muscles were bathed in

$186 \mathrm{a} \sim 26^{\circ} \mathrm{C}$ Tyrode solution with a $\mathrm{pH}$ of $\sim 7.4(121 \mathrm{mM} \mathrm{NaCL}, 24 \mathrm{mM} \mathrm{NaHCO} 3,5.5 \mathrm{mM}$ D-Glucose,

$1875 \mathrm{mM} \mathrm{KCl}, 1.8 \mathrm{mM} \mathrm{CaCl}_{2}, 0.5 \mathrm{mM} \mathrm{MgCl}_{2}, 0.4 \mathrm{mM} \mathrm{NaH}_{2} \mathrm{PO}_{4}, 0.1 \mathrm{mM}$ EDTA) that was bubbled

188 (Bonetta et al., 2015; Cheng and Westerblad, 2017) with a 95\% $\mathrm{O}_{2} / 5 \% \mathrm{CO}_{2}$ gas mixture (Praxair

189 Canada Inc., Kitchener, ON, Canada). A 701C High-Powered, Bi-Phase Stimulator (Aurora

190 Scientific, Aurora, ON, Canada) was used to evoke all contractions via two parallel platinum

191 electrodes submerged in the solution, situated on either side of the muscle. Force, length, and

192 stimulus trigger data were all sampled at $1000 \mathrm{~Hz}$ with a 605A Dynamic Muscle Data Acquisition

193 and Analysis System (Aurora Scientific, Aurora, ON, Canada). All data were analyzed with the

194 615A Dynamic Muscle Control and Analysis High Throughput (DMC/DMA-HT) software suite

195 (Aurora Scientific, Aurora, ON, Canada). 

resulted in $\sim 0.075 \mathrm{~N}$ of resting tension prior to beginning any protocols (Chen et al., 2020). was used in the remainder of mechanical testing. with maximal tetanic stimulation ( $0.3 \mathrm{~ms}$ pulse width, $1 \mathrm{~s}$ duration, $100 \mathrm{~Hz}$ frequency) delivered at each new length (Chen et al., 2020; Heslinga and Huijing, 1993). This was repeated until the muscle length that produced peak tetanic force $\left(\mathrm{L}_{0}\right)$ was reached. Construction of an active force-

206 length relationship was then completed to at least $\pm 2 \mathrm{~mm}$ with respect to Lo. To further 207 approximate/confirm Lo for the subsequent work loops, the muscle was stimulated at the initial $208 \mathrm{~L}_{\mathrm{O}} \pm 0.5 \mathrm{~mm}$. The final length for $\mathrm{L}_{\mathrm{O}}$ was measured from tie to tie (i.e., musculotendinous junction 209 to musculotendinous junction) using $150 \mathrm{~mm}(0.01 \mathrm{~mm}$ resolution) analog calipers (Marathon, 210 Vaughan, ON, Canada). Prior to each tetanic stimulation, 2 minutes (to allow for dissipation of 211 force transients owing to stress-relaxation) of resting force were obtained for construction of a 212 passive force-length relationship, and following each tetanic stimulation, the muscle was returned 213 to the original taut length (Heslinga and Huijing, 1993).

215 imposed about $\mathrm{L}_{\mathrm{O}}$ for each of 1.5, 2, and 3-Hz cycle frequencies (i.e., the frequency of the length 216 sinusoid) and 1, 3, 5, and 7-mm strains (e.g., a 3-mm strain indicates a displacement of $\pm 1.5 \mathrm{~mm}$ 217 from $\mathrm{L}_{\mathrm{O}}$ ). After piloting, we decided to not test the 7-mm strain at the 3-Hz cycle frequency 218 because the muscle sometimes slipped out of its ties with this combination of speed and stretch. 
219 The range of cycle frequencies was chosen because they correspond to a wide range of treadmill

220 running speeds for the rat $(<13$ to $67 \mathrm{~m} / \mathrm{min})$ and are consistent with cycle frequencies that occur

221 during spontaneous running (maximum $4 \mathrm{~Hz}$ ) (Caiozzo and Baldwin, 1997; Nicolopoulos-

222 Stournaras and Iles, 1983; Roy et al., 1991). The range of strains was chosen because they fall

223 within the maximum excursion of the rat soleus in vivo $(\sim 10 \mathrm{~mm})$ (Woittiez et al., 1985). The

224 cycle frequency and strain ranges we used are also comparable to those used in previous rat soleus

225 work loop studies (Caiozzo and Baldwin, 1997; Swoap et al., 1997).

A set of 3 consecutive work loops was performed at each cycle frequency: 1 passive work loop with no electrical stimulation to determine the work done against passive elements in the muscle (Cox et al., 2000; James et al., 1995); and 2 active work loops with stimulation (0.3 ms pulse width, $100 \mathrm{~Hz}$ frequency) set to begin at the onset of shortening (Swoap et al., 1997) and last for $70 \%$ of the shortening phase (i.e., duty cycle $=0.7$ ). Pilot testing determined that 2 consecutive active work loops sufficiently determined optimal net work: in a set of 3 active work loops, the highest net work occurred in the $1^{\text {st }}$ or $2^{\text {nd }}$ loop more than $80 \%$ of the time, and net work did not differ between each loop by $>10 \%$. Employing only 2 active work loops per set was also desirable

234 for minimizing the development of muscle fatigue and deterioration of tissue viability. Two 235 minutes of rest were always provided before proceeding to the next set of work loops (Swoap et 236 al., 1997).

Protocol D: Assessment for fatigue-induced force loss. Two minutes after the final work

238 loop, a maximal tetanic contraction performed at $\mathrm{L}_{\mathrm{o}}$, and a work loop at $1.5 \mathrm{~Hz}$ and $3 \mathrm{~mm}$ (i.e., the

239 loop determined to usually produce maximal net work output during piloting) were performed to 240 ensure that fatigue did not interfere with results. Fatigue was defined as a $>10 \%$ drop in these 241 parameters compared to baseline, and no muscles experienced this. 
243 the force-length relationship up to $2 \mathrm{~mm}$ on either side of $\mathrm{Lo}_{\mathrm{o}}$, at 1 -mm intervals. This 244 methodological limitation may have prevented us from observing adaptations such as a widening 245 of the force-length relationship plateau region (Akagi et al., 2020) or widening of the whole force246 length relationship (i.e., the operating range for active force) (Alder et al., 1958; De Koning et al., 247 1987; Woittiez et al., 1986). Such information may have been relevant in interpreting the work 248 loop results, as we would be able to better elucidate whether trained muscles were acting at near249 optimal force production across a wider range of muscle lengths than controls. However, due to 250 concerns of tissue viability we wanted to minimize time spent on the force-length relationship prior 251 to work loop protocols. We also only employed 1 passive work loop and 2 active work loops per 252 set in effort to preserve tissue viability for the duration of the experiment. There is likely some 253 viscosity present during the first loop that would be reduced in later cycles and yield different net 254 work output values. However, previous work loop studies on the rat soleus also employed as few as 3 total work loops per set in assessing net work output across a range of strains and cycle 256 frequencies (Swoap et al., 1997). Additionally, as our work loop methods were consistent across 257 work loop conditions (i.e., cycle frequency, strain) and between groups, it is unlikely that they 258 confounded comparisons across cycle frequencies, strains, and groups in this study. Muscle architecture and serial sarcomere number estimations. Following mechanical

260 testing, the muscle was removed from the bath, weighed, then passively stretched to the Lo 261 determined in Protocol B and tied to a wooden stick. The muscle was then fixed in 10\% phosphate262 buffered formalin for 48 hours, rinsed with phosphate-buffered saline, and digested in $30 \%$ nitric 263 acid for 6-8 hours to remove connective tissue and allow individual muscle fascicles to be teased 264 out (Butterfield et al., 2005; Chen et al., 2020). To obtain a global measure of SSN, 6 fascicles 
were obtained lateral to medial, superficial, and deep across the muscle. Dissected fascicles were placed on glass microslides (VWR International, USA), then fascicle lengths were measured using Image J software (version 1.53f, National Institutes of Health, USA) from pictures captured by a level, tripod-mounted digital camera, with measurements calibrated to a ruler that was level with the fascicles. Sarcomere length measurements were taken at six different locations along each fascicle via laser diffraction (Coherent, Santa Clara, CA, USA) with a 5-mW diode laser (25 $\mu \mathrm{m}$

271 beam diameter, $635 \mathrm{~nm}$ wavelength) and custom LabVIEW program (Version 2011, National 272 Instruments, Austin, TX, USA) (Lieber et al., 1984), for a total of 36 sarcomere length measurements per muscle. Serial sarcomere numbers were calculated as: pepsin-insoluble collagen quantifying the amount of collagen crosslinking (Brashear et al., 2020). The muscle was powdered in liquid nitrogen with a mortar and pestle, careful to remove any remaining tendon. The powdered muscle was then weighed and washed in $1 \mathrm{~mL}$ of phosphatebuffered saline and stirred for 30 minutes at $4^{\circ} \mathrm{C}$. Non-crosslinked collagen was digested in a 1:10 mass (mg of powdered tissue):volume $(\mu \mathrm{L})$ solution of $0.5 \mathrm{M}$ acetic acid with $1 \mathrm{mg} / \mathrm{mL}$ pepsin,

282 stirring overnight at $4^{\circ} \mathrm{C}$. After centrifuging at $16000 \mathrm{~g}$ for 30 minutes at $4^{\circ} \mathrm{C}$, the supernatant was 283 collected as the pepsin-soluble fraction (non-crosslinked collagen), and the pellet was kept as the 284 pepsin-insoluble fraction (crosslinked collagen). The two separate fractions were hydrolyzed overnight in $0.5 \mathrm{~mL}$ of $6 \mathrm{M}$ hydrochloric acid at $105^{\circ} \mathrm{C} .10 \mu \mathrm{L}$ of hydrolysate were mixed with

$286150 \mu \mathrm{L}$ of isopropanol followed by $75 \mu \mathrm{L}$ of $1.4 \%$ chloramine- $\mathrm{T}$ (ThermoFisher) in citrate buffer $287(\mathrm{pH}=6.0)$ and oxidized at room temperature for 10 minutes. The samples were then mixed with 
$2881 \mathrm{~mL}$ of a $3: 13$ solution of Ehrlich's reagent (1.5 $\mathrm{g}$ of 4-[dimethylamino] benzaldehyde

289 [ThermoFisher]; $5 \mathrm{~mL}$ ethanol; $337 \mu \mathrm{L}$ sulfuric acid) to isopropanol and incubated for $30 \mathrm{~min}$ at

$29058^{\circ} \mathrm{C}$. Quantification was determined by extinction measurement of the resulting solution at 550

$291 \mathrm{~nm}$. A standard curve $(0-1000 \mu \mathrm{M}$ trans-4-hydroxy-L-proline; Fisher) was included in each assay

292 (average linear $\mathrm{R}^{2}=0.98$ ), and samples were run in triplicate (average $\mathrm{CV}=0.098$ ).

293 Hydroxyproline concentrations in samples were determined by interpolation from the linear

294 equation of the corresponding assay's standard curve. Results are reported as $\mu \mathrm{g}$ of hydroxyproline

295 per mg of powdered tissue mass.

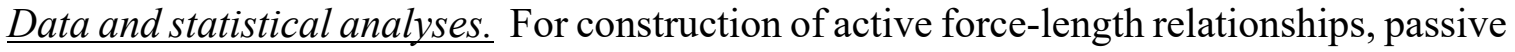

297 force values were subtracted from total force at each length to estimate active force production.

298 Passive force was taken from a 500-ms window prior to tetanic stimulation, and total force was

299 taken as the maximum force produced in the tetanic contraction. Average active and passive force-

300 length relationships for each group were constructed by averaging force values in length categories

301 with respect to $\mathrm{L}_{\mathrm{O}}$ (e.g., $\left.\mathrm{L}_{\mathrm{O}}-2,-1,0,+1,+2 \mathrm{~mm}\right)$.

From each work loop, Aurora Scientific software calculated work of shortening and work

303 of lengthening (the integrals under the shortening and lengthening curves, respectively, in a force-

304 length plot) and net work output of a whole cycle (the area inside the whole shortening and

305 lengthening cycle; work of shortening + work of lengthening, with work in the shortening direction

306 defined as positive). Of the two active work loops in a given set, the loop that produced the highest

307 net work was chosen for statistical analyses (Swoap et al., 1997). Since a relatively long duty

308 cycle (i.e., 0.7) may not have allowed full relaxation prior to lengthening in the active work loops,

309 the net work from a work loop with a more optimal duty cycle was also estimated by adding the

310 work of shortening (positive) in the active work loop and the work of lengthening (negative) in the 
311 corresponding passive work loop. These estimated values of optimal net work output will

312 henceforth be referred to as the "estimated optimal net work output."

All force and work values were normalized to the muscle's physiological cross-sectional area $\left(\mathrm{PSCA} ; \mathrm{cm}^{2}\right)$ to obtain specific values (expressed as units $\left./ \mathrm{cm}^{2}\right)$. PCSA was calculated as:

\section{$P C S A=$ muscle mass $/($ muscle density $\times$ fascicle length $)$}

With muscle density assumed to be $1.112 \mathrm{~g} / \mathrm{cm}^{3}$ (Ward and Lieber, 2005).

tests were used to compare body weights between control and trained rats throughout the training period (i.e., at $\sim 14,15,16,17$, and 18 weeks old). A one-way analysis of variance (ANOVA) with

a Holm-Sidak correction for all pairwise comparisons was used to compare FL, SL, SSN, $\mathrm{L}_{\mathrm{O}}$, muscle weight, PCSA, total collagen, and \% insoluble collagen between trained and control rats. hoc power analyses (t-tests, difference between two independent means; G*Power software) were performed on FL, SL, and SSN, with $80 \%$ indicating statistical power.

One control rat was determined to be an outlier for $\mathrm{L}_{\mathrm{O}}$ (being $2.09 \mathrm{~mm}$ greater than the third quartile +1.5 times the interquartile range) and was removed from all force-length relationship analyses (new sample size: $\mathrm{n}=16$ control, $\mathrm{n}=12$ training). Two-way ANOVAs

328 (group [training, control] $\times$ length with respect to $\mathrm{Lo}_{\mathrm{O}}\left[\mathrm{Lo}_{\mathrm{O}}-2,-1,+0,+1,+2 \mathrm{~mm}\right]$ ) with Holm-Sidak

329 corrections were used to compare active and passive force across the force-length relationship, and

330 between groups. Differences in active force at each length with respect to Lo were then compared

331 using one-way ANOVAs with Holm-Sidak corrections. Since the force-length relationship was

332 shifted rightward by on average $\sim 1 \mathrm{~mm}$ (see results), to determine if training reduced passive force

333 at a given muscle length, passive force values of control rats at a length with respect to Lo were 
compared to passive force at one less than that length for trained rats (e.g., control passive force at

passive force at $\mathrm{L}_{\mathrm{O}}+1 \mathrm{~mm}[\sim 25.7 \mathrm{~mm}]$ was compared to trained passive force at $\mathrm{L}_{\mathrm{O}}[\sim 25.7 \mathrm{~mm}]$, and so on) using a one-way ANOVA with a Holm-Sidak correction.

A three-way ANOVA (group [training, control] $\times$ cycle frequency $[1.5,2,3 \mathrm{~Hz}] \times$ strain

$[1,3,5,7 \mathrm{~mm}])$ with a Holm-Sidak correction for all pairwise comparisons was used to compare all work loop parameters from the passive and active work loops (work of shortening, work of

341 lengthening, net work output, estimated optimal net work output). An effect of group defined a

342 difference between control and trained rat work loops. Where effects of group were detected, oneway ANOVAs with Holm-Sidak corrections were employed to compare work loop parameters

344 between control and trained rats at specific cycle frequencies/strains. Two-tailed paired t-tests 345 were used to compare net work output between the recorded work loops and the estimated optimal 346 work loops.

force normalized to PCSA in both groups combined were performed to elucidate which training-

349 induced adaptations contributed to improvements in net work output. Multiple linear regression

350 with the variables that showed significant relationships with net work output was also performed 351 to further understand the relative importance of each in net work output. 


\section{Results}

358 in body weight between control and trained rats at any time points. As shown in Figure 2A-B,

trained and control rats $(\mathrm{F}(1,29)=2.33, P=0.14)$.
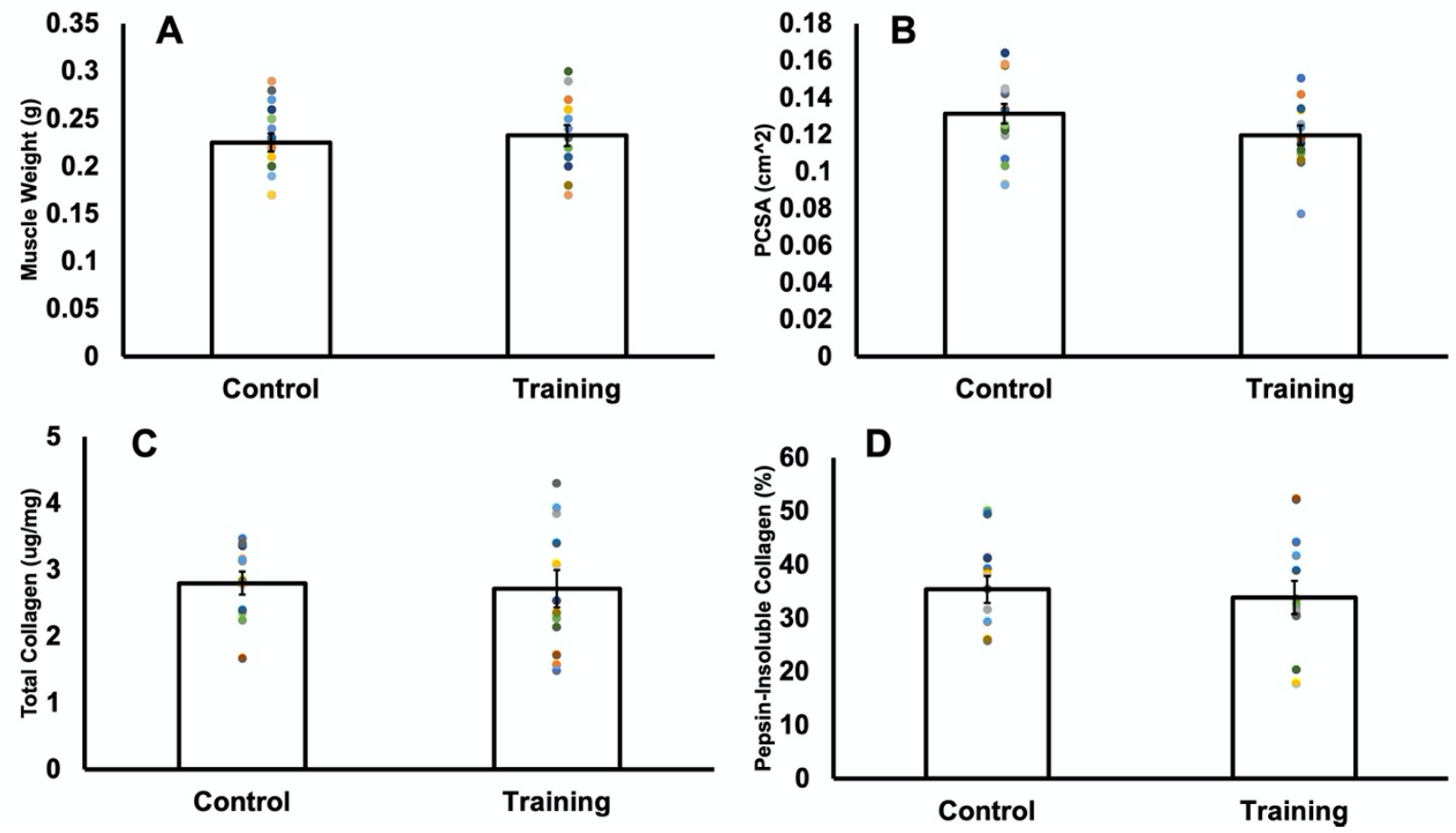

366 Figure 2: Comparison of muscle wet weight (A), physiological cross-sectional area (PCSA) (B), total collagen

367 concentration (C), and the percentage represented by pepsin-insoluble collagen (D) in control versus trained rats. Data

368 are reported as mean \pm standard error (A-B: $n=18$ control, $n=13$ training; C-D: $n=11$ control, $n=12$ training). No

369 significant differences $(P>0.05)$ were found between control and training for any of these variables. 
371 control and 13 trained rats. FL was $13 \%$ longer $(\mathrm{F}(1,29)=13.44, P<0.01, d=1.38)$ in trained

$372(17.52 \pm 1.60 \mathrm{~mm}, 95 \%$ CI [16.55,18.49]) than control rats $(15.47 \pm 1.49 \mathrm{~mm}, 95 \%$ CI

$373[14.72,16.21]$ ), implying a training-induced increase in FL (Figure 3A).
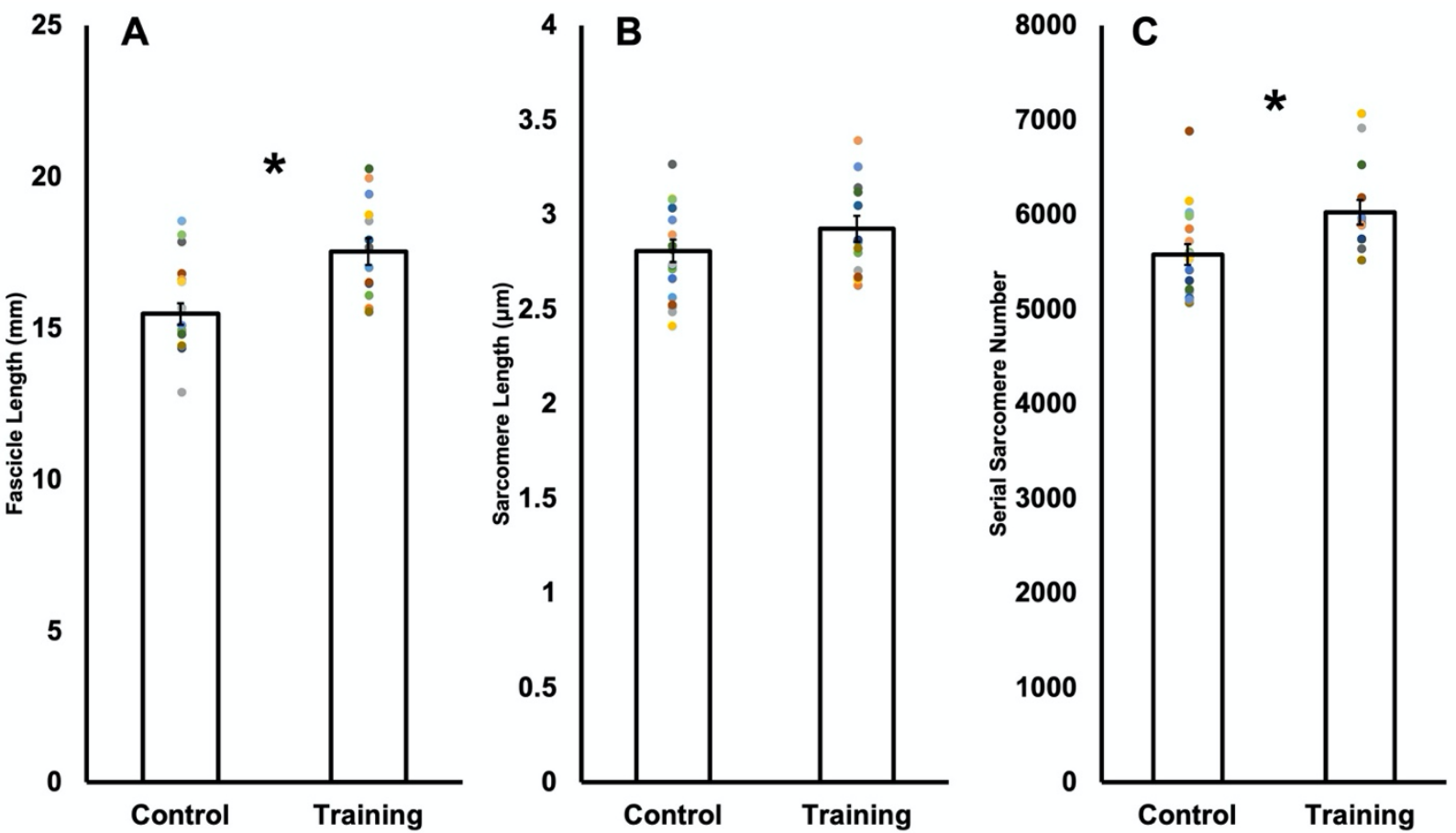

375 Figure 3: Comparison of fascicle length (A), sarcomere length (B), and serial sarcomere number (C) in control versus trained rats. Data are reported as mean \pm standard error $(\mathrm{n}=18$ control, $\mathrm{n}=13$ training $) .{ }^{*}$ Significant difference $(P$ $<0.05)$ between control and training.

For SL, 80\% power was not achieved using average SL in 18 control and 13 trained rats

379 (Power $=35 \%)$. With these sample sizes, SL did not differ $(\mathrm{F}(1,29)=1.73, P=0.20)$ between

380 trained $(2.93 \pm 0.25 \mu \mathrm{m}, 95 \% \mathrm{CI}[2.78,3.07])$ and control rats $(2.81 \pm 0.25 \mu \mathrm{m}, 95 \% \mathrm{CI}[2.69,2.94])$

381 (Figure 3B). A follow-up a-priori power analysis indicated 67 control and 49 trained rats would

382 be required to achieve statistical power for SL, which would not be feasible within time and ethical

383 constraints of this research. To obtain data closer to this sample size, we treated each fascicle

384 independently, amounting to 106 control and 78 trained measurements of average SL. Viewed 
this way, SL was $5 \%$ higher $(\mathrm{F}(1,182)=8.75, P<0.01, d=0.44)$ in trained $(2.94 \pm 0.29 \mu \mathrm{m}, 95 \%$ representative of individual fascicles as opposed to individual animals.
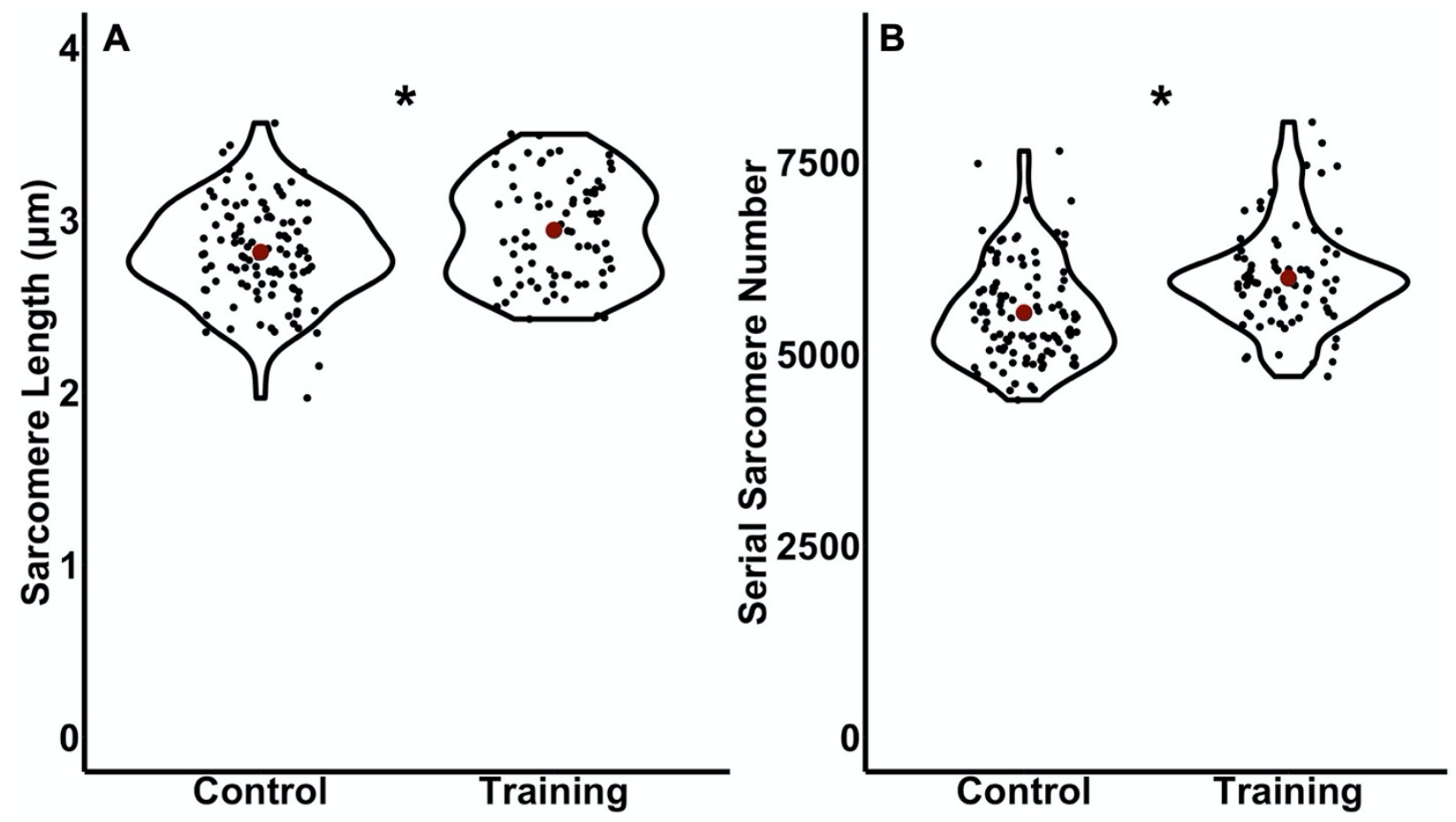

396 Figure 4: Violin plot comparisons of average sarcomere length (A) and serial sarcomere number (B) in control versus 397 trained rats with the sample size adjusted to treat each fascicle independently. Red dots represent the mean. $398 *$ Significant difference $(P<0.05)$ between control and training. 

difference $(\mathrm{F}(1,26)=1.48, P=0.23)$. There was an effect of group on specific active force $\left(\mathrm{F}(1,135)=27.09, P<0.01, \eta_{\mathrm{p}}{ }^{2}=0.18\right)$, with one-way ANOVA showing specific active force was $\sim 50 \%$ greater in trained than control rats at $\mathrm{Lo}_{-1} \mathrm{~mm}(\mathrm{~F}(1,26)=5.77, P=0.02, d=0.95), \mathrm{Lo}_{\mathrm{O}}$ $(\mathrm{F}(1,26)=5.88, P=0.02, d=0.96), \mathrm{Lo}_{\mathrm{O}}+1 \mathrm{~mm}(\mathrm{~F}(1,26)=6.19, P=0.02, d=0.99)$, and $\mathrm{Lo}_{\mathrm{O}}+2 \mathrm{~mm}$ $(\mathrm{F}(1,22)=6.15, P=0.02, d=1.07)$. There was no effect of muscle length with respect to Lo on specific active force $(\mathrm{F}(4,135)=0.36, P=0.84)$, suggesting active force did not significantly differ between $\mathrm{L}_{\mathrm{O}}$ and the other muscle lengths tested, however, when comparing force values normalized to maximum force, there was an effect of muscle length with respect to $\mathrm{L}_{\mathrm{O}}(\mathrm{F}(4,133)$ $\left.=26.37, P<0.01, \eta_{\mathrm{p}}{ }^{2}=0.46\right)$, and force differed from force at adjacent points at all muscle lengths tested (all comparisons $P<0.01$ ) (Figure 5A).

$413\left(\mathrm{~F}(1,136)=29.52, P<0.01, \eta_{\mathrm{p}}{ }^{2}=0.22\right)$ and force normalized to maximum active force $(\mathrm{F}(1,133)$

$\left.414=12.85, P<0.01, \eta_{\mathrm{p}}^{2}=0.10\right)$ in the passive force-length relationship. Particularly, specific passive

415 force was $45-62 \%$ less in trained than control rats at $\sim 23.7 \mathrm{~mm}(\mathrm{~F}(1,26)=7.34, P=0.01, d=1.07)$,

$416 \sim 24.7 \mathrm{~mm}(\mathrm{~F}(1,26)=7.53, P=0.01, d=1.09), \sim 25.7 \mathrm{~mm}(\mathrm{~F}(1,26)=7.39, P=0.01, d=1.08)$, and

$417 \sim 26.7 \mathrm{~mm}(\mathrm{~F}(1,25)=8.63, P<0.01, d=1.16)$ (Figure 6D). Passive force normalized to maximum

418 was $26 \%$ less in trained than control rats at $\sim 25.7 \mathrm{~mm}(\mathrm{~F}(1,26)=4.61, P=0.04, d=0.85)$ and

$419 \sim 26.7 \mathrm{~mm}(\mathrm{~F}(1,25)=14.10, P<0.01, d=1.51)$ (Figure 6B). Last, there was an effect of muscle

420 length with respect to $\mathrm{L}_{\mathrm{O}}$ on specific passive force $\left(\mathrm{F}(4,135)=26.10, P<0.01, \eta_{\mathrm{p}}{ }^{2}=0.46\right)$ and

421 passive force normalized to maximum $\left(\mathrm{F}(4,133)=4.41, P<0.01, \eta_{\mathrm{p}}{ }^{2}=0.13\right)$, such that force 
422 differed between adjacent points at all muscle lengths tested (all comparisons $P<0.05$ ), 423 confirming passive force increased with increasing muscle length.
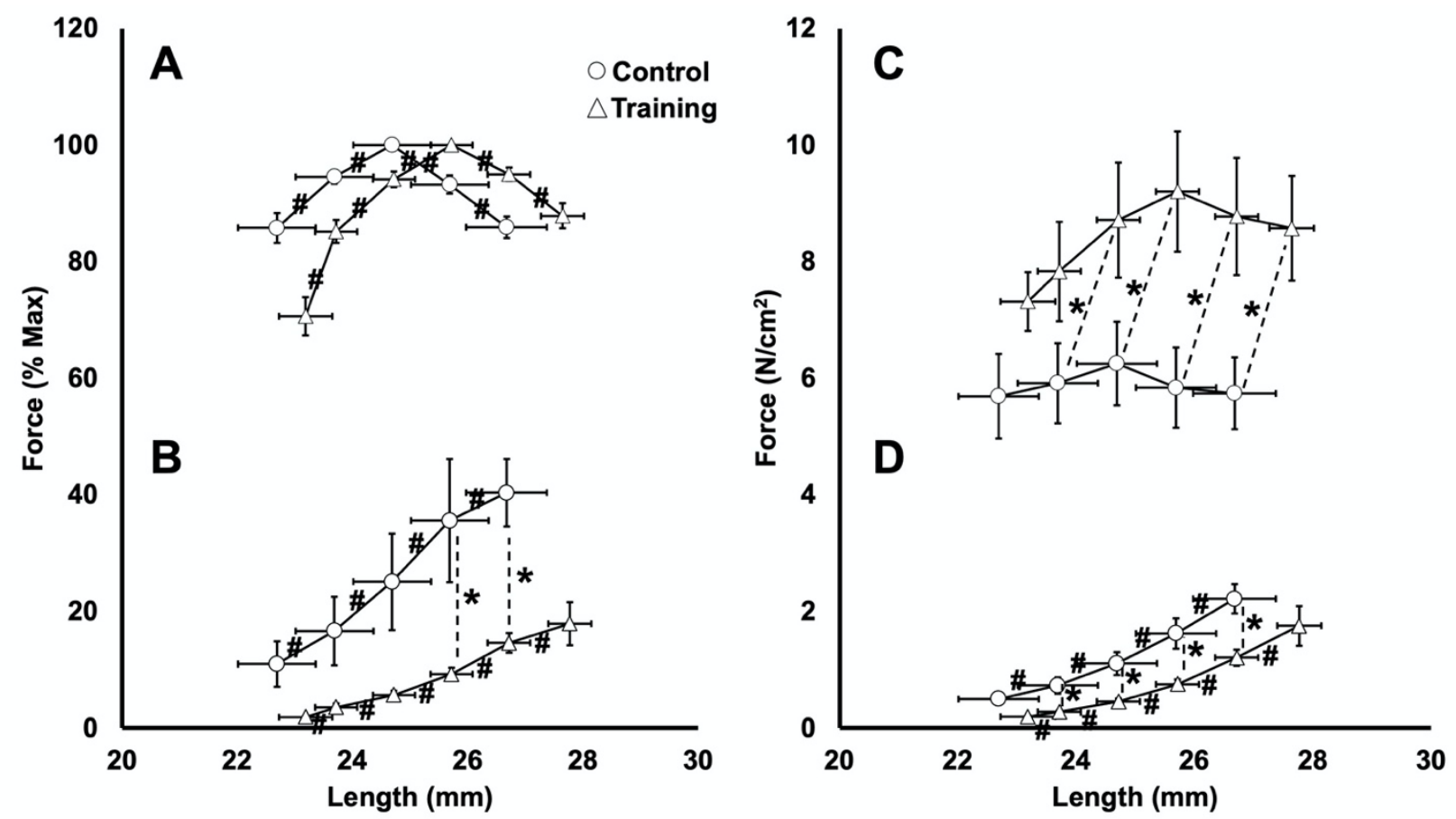

425 Figure 5: Comparison of average active (A and C) and passive (B and D) force-length relationships in control versus 426 trained rats, expressed as percent of maximum active force (left) and force normalized to physiological cross-sectional 427 area (right). Data are reported as mean \pm standard error $(\mathrm{n}=16$ control, $\mathrm{n}=12$ training). $*$ Significant difference $(P$ $428<0.05)$ between control and training. \#Significant difference in force between muscle lengths.

429 Passive work loops. All passive work loops were clockwise in shape such that work of 430 lengthening exceeded work of shortening (Figure S2). There were no effects of group $(\mathrm{F}(1,304)$ $431=0.00-2.07, P=0.15-0.99)$, nor group $\times$ cycle frequency $\times$ strain $(\mathrm{F}(5,304)=0.08-0.10, P=0.99-$ $4321.00)$, group $\times$ cycle frequency $(\mathrm{F}(2,304)=0.04-0.14, P=0.87-0.96)$, or group $\times \operatorname{strain}(\mathrm{F}(3,304)$ $433=0.09-0.67, P=0.57-0.97)$ interactions for work of shortening, work of lengthening, or net work 434 output, indicating similar passive work loops between control and trained rats at each cycle 435 frequency and strain (Figure 6). 
437 frequency $\times$ strain interactions $(\mathrm{F}(5,304)=0.02-0.38, P=0.86-0.98)$ on work of shortening, work

438 of lengthening, or net work output in the passive work loops, indicating they did not differ between

439 cycle frequencies at any strain. There were, however, effects of strain on all these parameters

$440 \quad\left(\mathrm{~F}(3,304)=71.10-85.57, P<0.001, \eta_{\mathrm{p}}{ }^{2}=0.43-0.48\right)$, such that work of shortening and work of

441 lengthening increased, and net work output decreased (i.e., became more negative) as strain

442 increased (all comparisons $P<0.02$ ) (Figure 6).
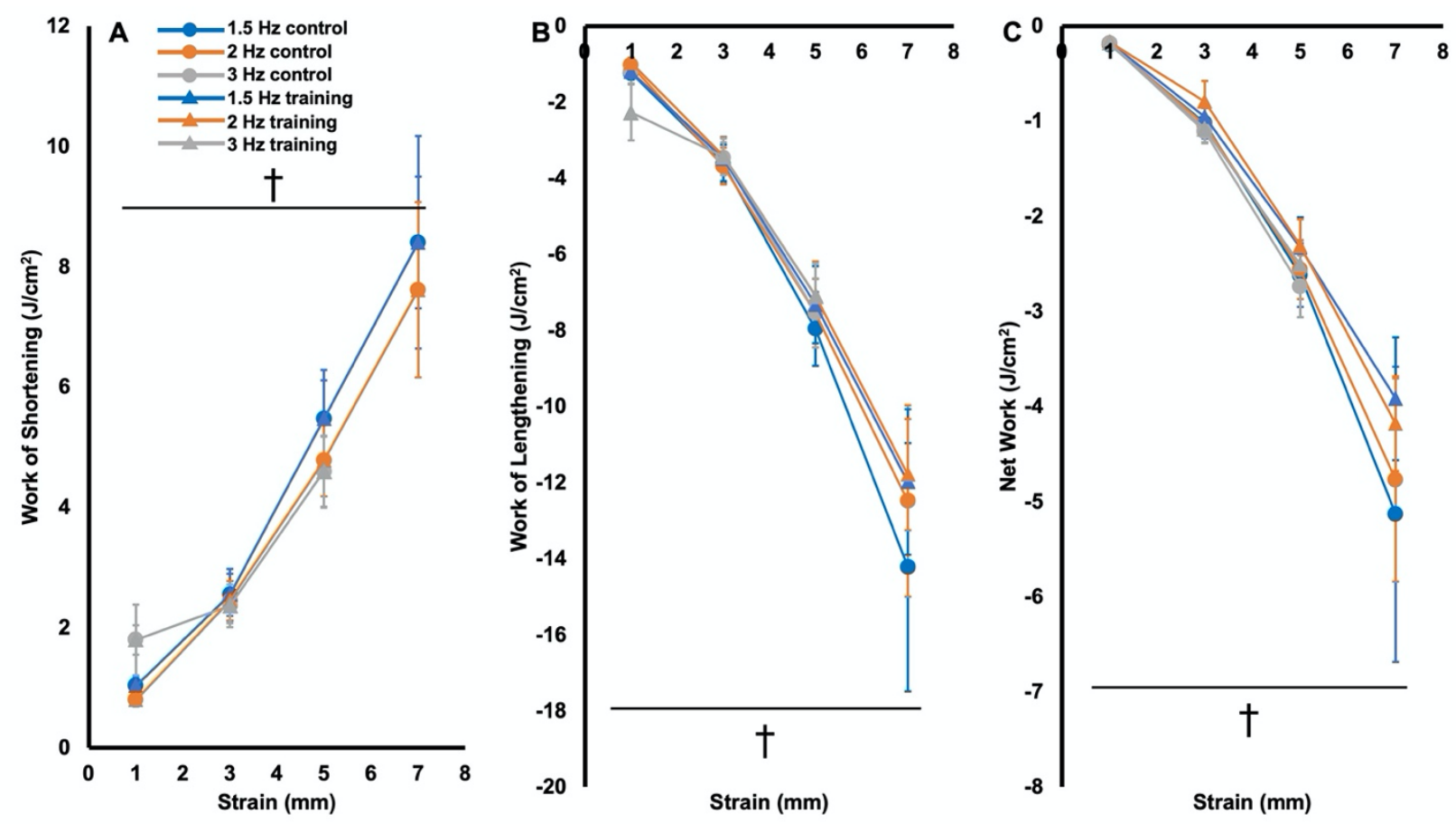

444 Figure 6: Work of shortening (A), work of lengthening (B), and net work output (C) of the passive (i.e., no 445 stimulation) work loops in trained and control rats. Data are reported as mean \pm standard error $(\mathrm{n}=16$ control, $\mathrm{n}=12$ training). † Significant difference across strains.

Active work loops. Figure 7 shows representative work loop traces from 1 control and 1

trained rat. In general, work loops were mostly counterclockwise (i.e., containing primarily 
450 increasingly clockwise (i.e., containing negative work) with the work to re-lengthen the muscle

451 exceeding the work of shortening.
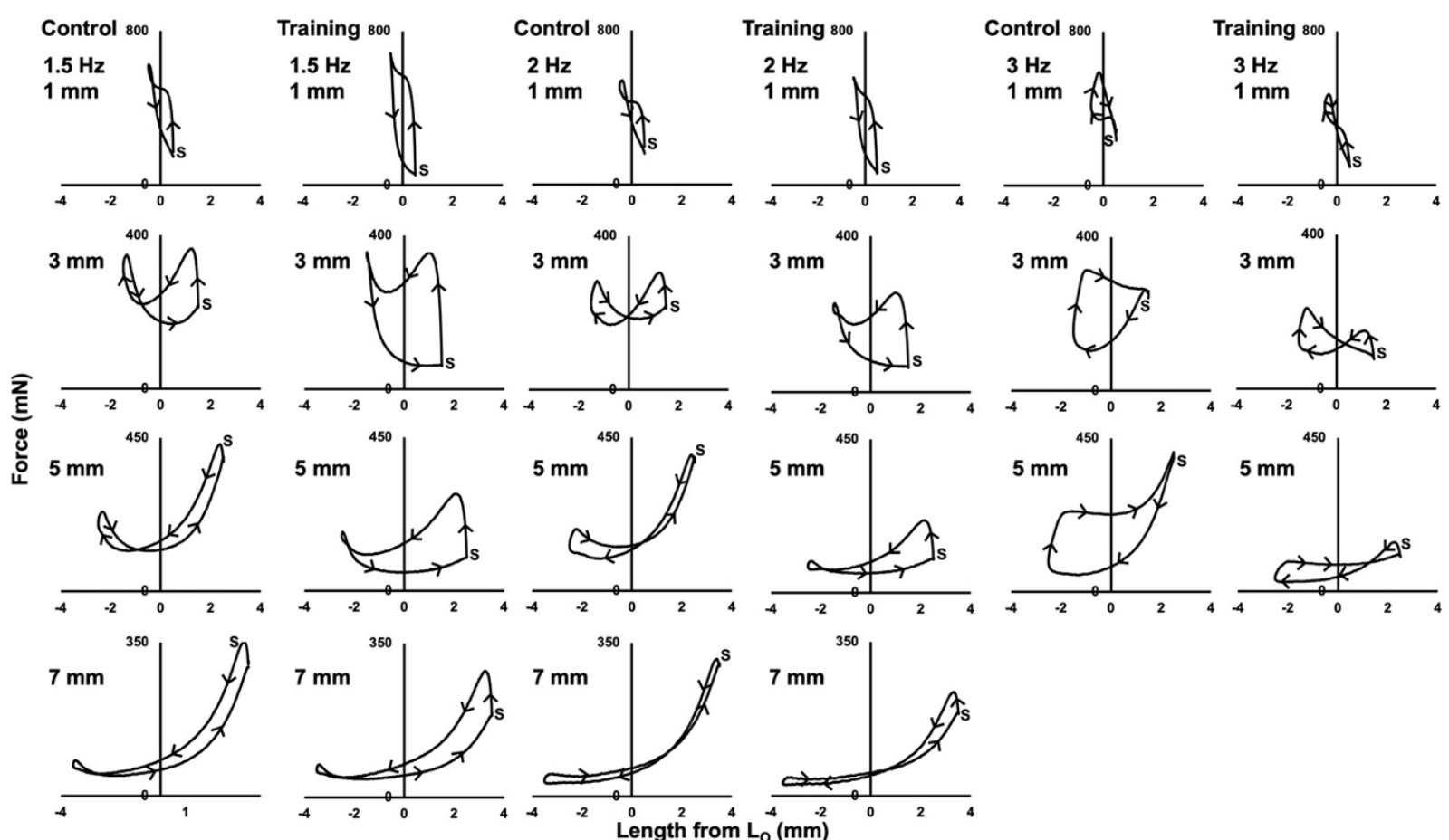

Figure 7: Representative active (i.e., stimulation during shortening) work loop traces from 1 control and 1 trained rat.

$454 S$ indicates the start of the cycle. Arrows indicate the direction of the cycle, with clockwise segments containing negative work and counterclockwise segments containing positive work.

As shown in Figure 8C, control rats on average produced maximal net work in the $1.5-\mathrm{Hz}$ cycle at a 1-mm strain while trained rats produced maximal net work at $1.5 \mathrm{~Hz}$ and $3 \mathrm{~mm}$, demonstrating a training-induced shift in the optimal strain at $1.5 \mathrm{~Hz}$. Supporting training-induced changes in maximal net work output, there was an effect of group on net work output $(\mathrm{F}(1,304)=$ 9.19, $\left.P<0.01, \eta_{\mathrm{p}}{ }^{2}=0.03\right)$, with trained rats producing on average $0.98 \mathrm{~J} / \mathrm{cm}^{2}(95 \% \mathrm{CI}[0.36,1.61])$

461 more net work than controls across all work loop conditions. However, there were no interactions

462 of group $\times$ cycle frequency $\times \operatorname{strain}(\mathrm{F}(5,304)=0.08 P=1.00)$, group $\times$ cycle frequency $(\mathrm{F}(2,304)$ $463=0.98, P=0.38)$, or group $\times \operatorname{strain}(\mathrm{F}(3,304)=0.47, P=0.70)$, indicating the effect of group on 
465 effect of group was most pronounced in 1.5-Hz work loops, with trained rats producing $101 \%$

466 greater net work output than controls at the $1-\mathrm{mm}$ strain $(\mathrm{F}(1,26)=6.42, P=0.02, d=1.00), 246 \%$

467 greater net work output at the $3-\mathrm{mm}$ strain $(\mathrm{F}(1,26=4.92, P=0.04, d=0.88)$, and $424 \%$ greater

net work output at the $5-\mathrm{mm}$ strain $(\mathrm{F}(1,26=4.32, P<0.05, d=0.82)$ (Figure 8C).

469
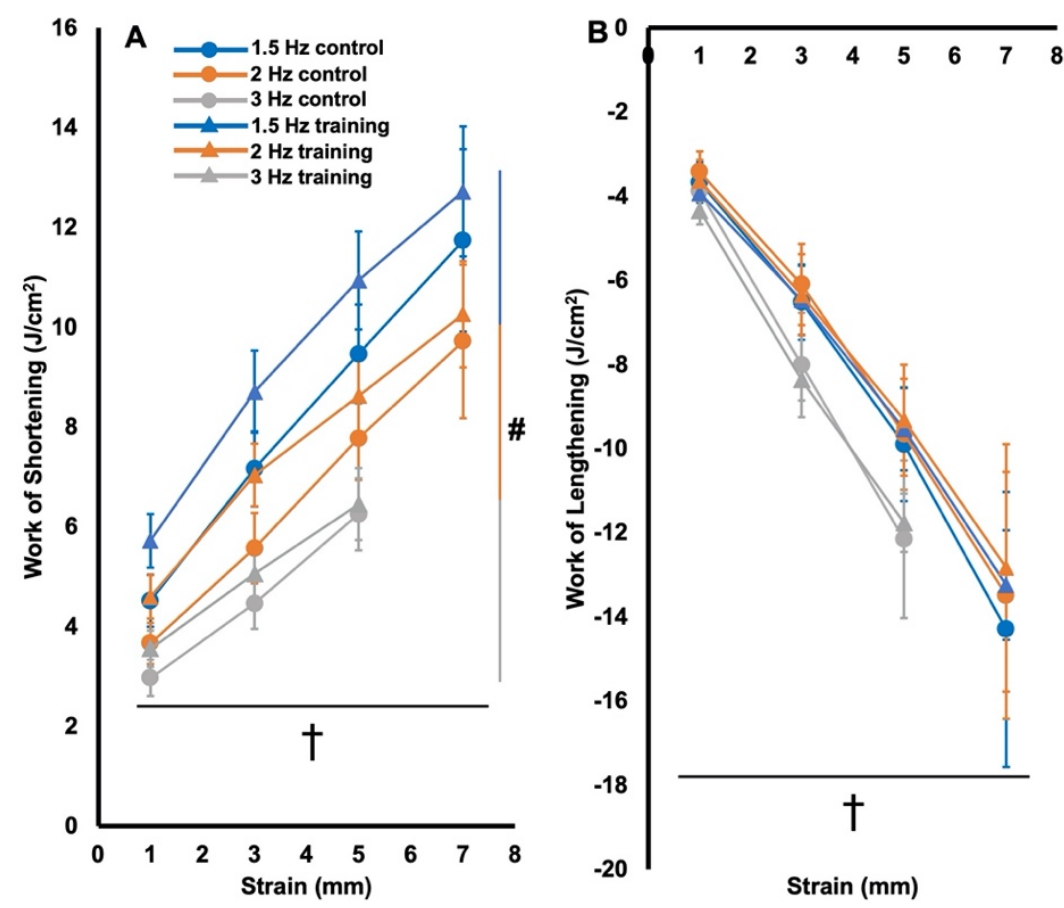

Figure 8: Work of shortening (A), work of lengthening (B), and net work output (C) of the active (i.e., stimulation during shortening) work loops in trained and control rats. Data are reported as mean \pm standard error $(\mathrm{n}=16$ control, $\mathrm{n}=12$ training). *Significant difference $(P<0.05)$ between control and training at the colour-coded cycle frequency. \#Significant difference across cycle frequencies. †Significant difference across strains.

There was an effect of group on work of shortening $\left(\mathrm{F}(1,304)=5.52, P=0.02, \eta_{\mathrm{p}}{ }^{2}=0.02\right)$ (Figure $8 \mathrm{~A}$ ) but not work of lengthening $(\mathrm{F}(1,304)=0.06 P=0.81)$ in the active work loops (Figure $8 \mathrm{~B})$, suggesting differences in work of shortening between groups contributed more to the differences in net work output, with trained rats producing on average $0.94 \mathrm{~J} / \mathrm{cm}^{2}$ (95\% CI $[0.21$, 1.68]) more work of shortening than controls across all work loops. Neither work of shortening or work of lengthening showed interactions of group $\times$ cycle frequency $\times \operatorname{strain}(F(5,304)=0.01$ - 
$0.02 P=1.00)$, group $\times$ cycle frequency $(\mathrm{F}(2,304)=0.01-0.49, P=0.61-0.99)$, or group $\times$ strain

$(\mathrm{F}(3,304)=0.12-0.14, P=0.93-0.95)$. Despite there being an effect of group on work of

shortening, post-hoc tests did not reveal significant differences in work of shortening between trained and control rats in any work loops.

There were also effects of cycle frequency on work of shortening and net work output, $\left(\mathrm{F}(2,304)=20.37-59.51, P<0.01, \eta_{\mathrm{p}}{ }^{2}=0.13-0.30\right)$, but not work of lengthening $(\mathrm{F}(2,304)=2.42$, $P=0.09)$. There were effects of strain on all these variables $(\mathrm{F}(3,304)=26.95-43.68, P<0.01$, $\eta_{\mathrm{p}}{ }^{2}=0.22-0.32$ ). Specifically, work of shortening decreased with increasing cycle frequency (all comparisons $P<0.01$ ), and work of shortening and work of lengthening both increased with strain (all comparisons $P<0.01$ ) (Figure 8A-B). Net work output decreased with increasing cycle frequency (all comparisons $P<0.01$ ), and with increasing strain past the optimal strain, except for between $5 \mathrm{~mm}$ and $7 \mathrm{~mm}(P=1.00$; all other comparisons $P<0.01$ to 0.05$)$ (Figure 8C). strain in active and passive work loops, and net work output decreased (i.e. became more negative) with strain on either side of the optimal strain. Increasing cycle frequency decreased work of

497 shortening and net work output, but did not change work of lengthening in the active work loops, and had no effect on any variables in the passive work loops.

501 between SSN and net work output in any work loops. There were, however, significant 502 relationships between net work output and $\mathrm{FL}(\mathrm{F}(1,27)=4.39-9.97, P=0.01-0.04)$, and net work 
503 output and SL $(\mathrm{F}(1,27)=4.87-13.77, P>0.01-0.04)$ in the work loops that significantly differed

504 between groups (i.e., $1.5 \mathrm{~Hz}$ at 1, 3, and 5-mm strains), such that FL explained 14\% to $28 \%$ and

505 SL explained $16 \%$ to $35 \%$ of the variation in net work output (Figure 9A-B). Regression analyses

506 for all other work loops showed no significant relationships with FL or SL.

507 There were significant relationships between specific maximum isometric force and net

508 work output only in the $1.5-\mathrm{Hz}$ work loops at 1 and $3-\mathrm{mm}$ strains $(\mathrm{F}(1,27)=5.59-20.55, P<0.01-$

509 0.03), such that specific maximum isometric force explained $18-44 \%$ of the variation in net work

510 output (Figure 9C). Beta coefficients from multiple linear regression revealed specific maximum

511 isometric force contributed more to work loop performance at the 1-mm strain, while FL and SL

512 were more important at the 3 and 5-mm strains (Figure 9). 

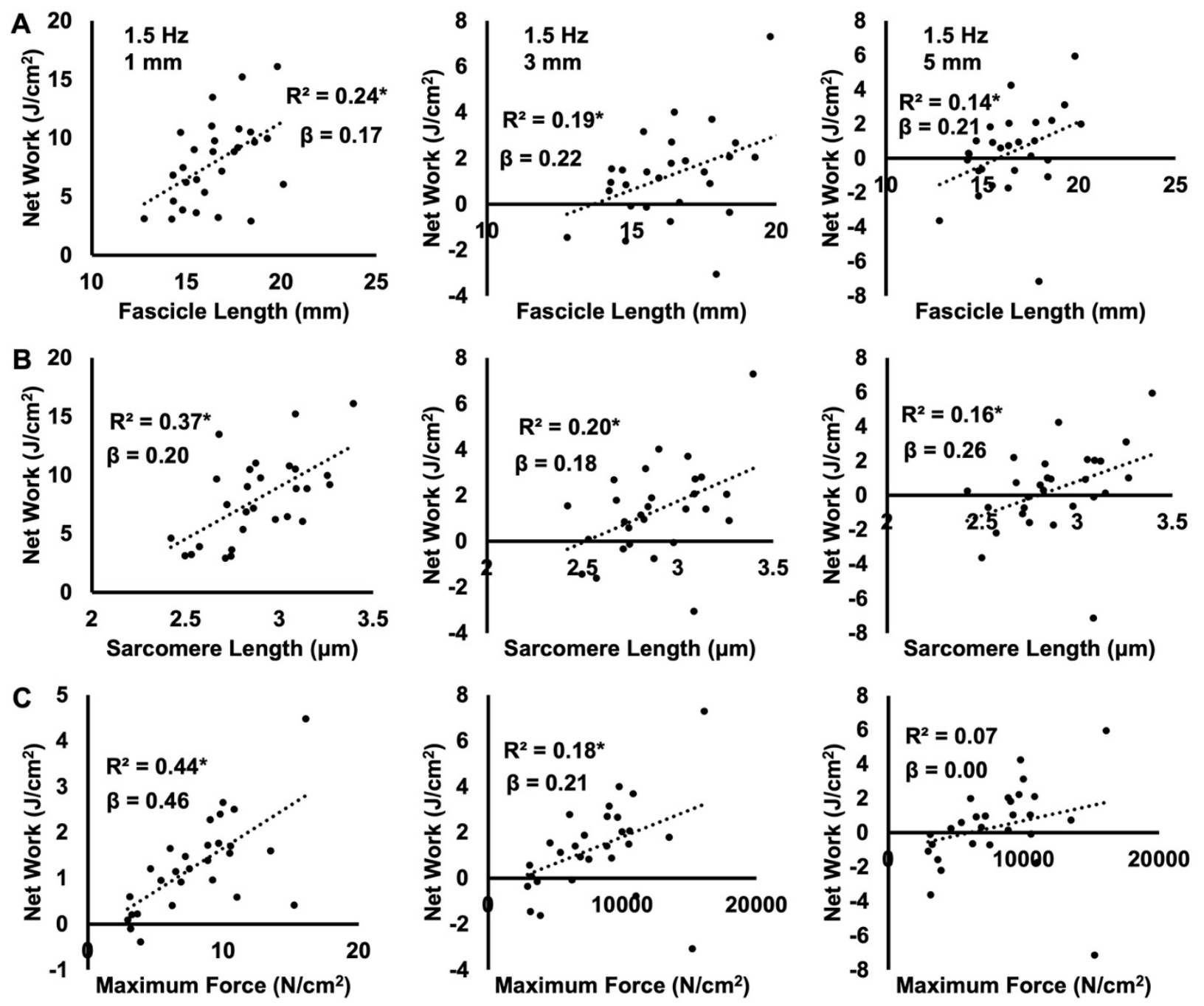

514 Figure 9: Plots of the relationships between net work output and fascicle length (A), sarcomere

515 length (B), and maximum isometric force normalized to physiological cross-sectional area (C) in

516 the $1.5-\mathrm{Hz}$ work loops at strains of 1,3 , and $5 \mathrm{~mm}$. *Significant relationship $(P<0.05)$. 


\section{Discussion}

This study assessed rat soleus architecture following 4 weeks of weighted downhill running

520 training and aimed to relate muscle architectural adaptations to changes in dynamic contractile

521 function, namely work loop performance. Our hypothesis that training would increase SSN, not

522 change collagen content and crosslinking, and increase net work output especially in work loops

523 with longer strains and faster cycle frequencies was partly correct. Comparing trained and control

524 rats, FL and SSN increased with training, as did SL but only when treating every fascicle

525 independently to increase the sample size. There were no differences in collagen parameters

526 between groups, and improvements in net work output were most pronounced in $1.5-\mathrm{Hz}$ work

527 loops at strains of 1,3 , and $5 \mathrm{~mm}$.

Did weighted downhill running training induce sarcomerogenesis?

The FL, SL, and SSN values in this study are within ranges of those recorded previously

531 for the rat soleus (Aoki et al., 2009; Baker and Hall-Craggs, 1978; Chen et al., 2020; Jakubiec-

532 Puka and Carraro, 1991; Koh and Tidball, 1999). It should be noted that we only characterized

533 global SSN of the soleus, thus any regional differences in SSN adaptations (Butterfield and

534 Herzog, 2006) are beyond the scope of this study.

535 We observed an $8 \%$ training-induced increase in SSN. This magnitude of

536 sarcomerogenesis is greater than what Chen et al. (2020) observed in the rat soleus following

537 unweighted downhill running compared to controls (an insignificant $+3 \%$ ). Butterfield and Herzog

538 (2006) showed the magnitude of SSN increase is strongly related to peak force developed during

539 eccentric contractions. Therefore, compared to Chen et al. (2020), the weighted vests employed

540 in the present study may have enhanced the eccentric load while running downhill, resulting in a 
541 greater stimulus for sarcomerogenesis. In the present study, rats also ran 3 days/week (Monday,

542 Wednesday, Friday) rather than the 5 days/week (Monday-Friday) used by Chen et al. (2020), and

543 the extra recovery days may have allowed more time for adaptations to occur between exercise

544 bouts (Hyldahl and Hubal, 2014).

The most accepted hypothesis for sarcomerogenesis (i.e., an increase in SSN) stems from

546 the active force-length relationship of muscle, whereby active force production is suboptimal in

547 over-stretched positions due to limited actin-myosin binding (Gordon et al., 1966a; Gordon et al.,

548 1966b), and observations that a muscle's average SL operating range favours force production for

549 particular task demands (Lieber and Ward, 2011; Lutz and Rome, 1994; Rome, 1994). It follows

550 that if a muscle is repeatedly forced to operate with overstretched sarcomeres (i.e., with eccentric

551 training), SSN would increase to maintain optimal actin-myosin overlap regions in that position

552 (Koh, 1995; Lynn et al., 1998; Williams and Goldspink, 1978). These adaptations relate to a

553 muscle's ability to sense a change in tension (in this case increased tension at a long muscle length),

554 then convert that mechanical signal into biochemical events regulating gene expression and protein

555 synthesis (Aoki et al., 2009; Bogomolovas et al., 2021; Franchi et al., 2018; Herring et al., 1984;

556 Soares et al., 2007; Spletter et al., 2018).

The $13 \%$ FL increase we observed with weighted downhill running training appears to

558 have been driven by increases in both SSN (+8\%) and SL (+4-5\%). This may be interpreted in

559 two ways. First, as optimal SL is generally believed to be constant within a species (Gokhin et al.,

560 2014; Walker and Schrodt, 1974), the roles of increased SL and SSN in increasing FL are likely

561 not mutually exclusive, but rather depend on the time course of adaptations (Herzog and Fontana,

562 2021; Zöllner et al., 2012). This perspective is illustrated by Barnett et al. (1980), who stretched

563 the patagialis muscle of chickens for 10 days. At 24 hours, the researchers observed a $40 \%$ 
564 increase in biceps brachii SL, however, SL decreased back to normal by 72 hours, with instead an

565 increase in SSN. Jahromi and Charlton (1979) explained this phenomenon by transverse myofibril

566 splitting, whereby an overstretched sarcomere eventually splits at its H-zone, then two new

567 sarcomeres develop from the split halves. It is therefore possible in the present study that at the 4-

568 week mark, some sarcomeres were at the point of stretching (i.e., increasing SL), while others had

569 separated such that new sarcomeres could be added (i.e., increasing SSN).

On the other hand, as we measured SL at Lo, we may have observed an increase in optimal

571 SL, which could imply elongation of the myofilaments within the sarcomere (Gokhin et al., 2014).

572 In this regard, it is difficult to compare to previous studies on sarcomerogenesis, as most fixed

573 their muscles in formalin at a set joint angle rather than at Lo (Roy et al., 1982; Salzano et al.,

574 2018; Tabary et al., 1972; Williams and Goldspink, 1978). These studies reported on average

575 approximately the same or shorter SLs in the experimental compared to control muscles.

576 Therefore, it is hypothetically possible that, had they fixed the muscles at Lo (i.e., a longer length

577 compared to the control muscle), they would have observed a longer optimal SL. This perspective

578 is somewhat supported by other studies that fixed muscles at Lo. Shrager et al. (2002) induced

579 emphysema in the lungs of rats, then 5 months later performed lung volume reduction surgery to

580 treat the emphysema. Another 5 months later, the diaphragms of rats who received lung volume

581 reduction surgery had a 14\% higher SSN and a 2\% longer optimal SL than untreated rats $(2.95 \mu \mathrm{m}$

582 versus $2.88 \mu \mathrm{m}$ ). Coutinho et al. (2004) fixed the rat soleus at resting length, which they assumed

583 to be $\mathrm{L}_{\mathrm{O}}$, following 3 weeks of immobilization in a shortened position with intermittent stretching.

584 Although they observed a decrease in SSN (due to being immobilized in a shortened position),

585 they observed a $\sim 2 \%$ increase in SL compared to controls $(2.2 \mu \mathrm{m}$ versus $1.9 \mu \mathrm{m})$. Lastly, Chen

586 et al. (2020) fixed the rat soleus at a measured Lo and observed on average a greater SL in downhill 
running rats than controls $(2.77 \pm 0.09 \mu \mathrm{m}$ versus $2.75 \pm 0.11 \mu \mathrm{m})$. Future research might aim to assess the time course of SL and SSN adaptations during training, or single-fiber testing to confirm optimal SLs to better understand these observations.

Did weighted downhill running training induce muscle hypertrophy?

PCSA between trained and control rats, possibly because there was still a strong endurance

601 which may provide insight into PCSA (Farup et al., 2012). If attempting to employ resistance training in rodents, future research might choose to investigate training programs closer to that of Zhu et al. (2021), in which mice pulled progressively overloaded carts down a track to failure, 604 inducing large increases in muscle wet weight. maximum isometric force production (Haun et al., 2019; Narici et al., 2016). We observed 50\% greater maximum isometric force normalized to PCSA at $\mathrm{L}_{\mathrm{O}}$ and 3 other muscle lengths in trained compared to control rats. These data imply training improved characteristics associated with the 
610 crossbridge, or myosin density (i.e., number of crossbridges), which may improve with physical

611 activity (Fitts et al., 1991; Xu et al., 2018) and resistance training (Łochyński et al., 2021).

Did sarcomerogenesis impact force-length relations?

Although statistically insignificant, we observed on average a $4 \%(\sim 1 \mathrm{~mm})$ greater $\mathrm{L}_{\mathrm{O}}$ in

615 trained than control rats. With an increase in SSN, Lo is expected to shift to a muscle length

616 previously on the descending limb (Davis et al., 2020; Koh, 1995). Rightward shifts in Lo of 5-

$61712 \%$ have been observed alongside $7-20 \%$ increases in SSN in studies on animals via

618 immobilization in a stretched position, high-acceleration training, isokinetic eccentric training, and

619 downhill running training (Butterfield and Herzog, 2006; Lynn et al., 1998; Salzano et al., 2018;

620 Williams and Goldspink, 1978). The downhill running study (Lynn et al., 1998) assessed the joint

621 torque-angle (i.e., not muscle force-length) relationship of the knee extensors, so is difficult to

622 compare to the present study. Chen et al. (2020), though, employed downhill running training and

623 observed no difference in rat soleus Lo compared to controls, and on average a $1.5 \%$ (also

624 insignificant) greater $\mathrm{L}_{\mathrm{O}}$ compared to uphill running rats. Like with SSN, the present study's

625 addition of weighted vests and extra rest days between training sessions may have amounted to a

626 greater shift in rat soleus Lo compared to unweighted downhill running training.

627 Changes to the passive force-length relationship were more noticeable than changes to the

628 active force-length relationship. Specifically, trained rats generated $45-62 \%$ less passive force at

$629 \sim 23.7,24.7,25.7$, and 26.7-mm muscle lengths. With a greater SSN, individual sarcomeres may

630 stretch less during muscle displacement, leading to less passive force generated by sarcomeric

631 proteins such as titin (Herbert and Gandevia, 2019). Noonan et al. (2020) demonstrated this with

632 lower passive stress and passive elastic modulus at longer SLs in soleus single fibers of rats that 
633 ran downhill compared to uphill. Noonan et al. (2020) used the same rats as Chen et al. (2020),

634 therefore the lower passive stress and elastic modulus appeared to be due to a $6 \%$ greater SSN.

635 The influence of sarcomerogenesis on the passive length-tension relationship is not always

636 predictable due to the concurrent involvement of intramuscular collagen in passive force

637 generation (Gillies and Lieber, 2011). For example, in studies on animals with sarcomerogenesis

638 induced via surgically stretching a muscle, the passive force-length relationship steepens compared

639 to controls due to concurrent increases in collagen content (Herbert and Balnave, 1993; Takahashi

640 et al., 2012). Age-related increases in passive muscles stiffness are also related to increased

641 collagen crosslinking in mice (Brashear et al., 2020). We observed no differences in collagen

642 content or crosslinking in trained compared to control rats, with our values of hydroxyproline

643 concentration falling into ranges of previous studies for the rat soleus (Karpakka et al., 1992;

644 Sugama et al., 1999). Han et al. (1999) observed no change in collagen content in the rat soleus

645 following downhill running, but also observed increases in some mRNAs and enzymes related to

646 collagen synthesis; however, these were following only a single bout of exercise. Perhaps more

647 comparable to the present study, Zimmerman et al. (1993) observed no changes in soleus collagen

648 content or crosslinking in 20 -week-old rats following 10 weeks of uphill running training. A

649 rightward shift in the passive force-length relationship alongside increased SSN and no change in

650 collagen content was also observed following passive stretch training of the rabbit soleus (De

651 Jaeger et al., 2015). Altogether, the present study's training-induced sarcomerogenesis appeared

652 to reduce passive tension at longer muscle lengths.

653

654 Is the work loop data comparable to previous studies on the rat soleus? 
$\sim 0.45$ at $3 \mathrm{~Hz}$ (Swoap et al. 1997)). Consequently, full relaxation did not occur prior the

658 lengthening phase in many of the active work loops, leading to some active lengthening force

659 development and partly, if not fully (i.e., at $3 \mathrm{~Hz}$ ), clockwise work loops (Figure 7). While we did

660 not collect the most optimal possible work loops, stimulation parameters were consistent between

661 control and trained rats, and as force was measured during muscle displacement, the data can be

662 interpreted in the context of muscle architecture to address our research question. Furthermore, to

663 bolster comparisons with prior studies, we estimated what net work output might have been under

664 better stimulation conditions by subtracting work of lengthening in the passive work loops from

665 work of shortening in the active work loops (Figure S3). When graphing these values of estimated

666 optimal net work output across strain and cycle frequency, the graph is similar in shape to previous

667 reports for the rat soleus (Caiozzo and Baldwin, 1997; Swoap et al., 1997). Additionally, the work

668 loops we obtained that were counter-clockwise (e.g., Figure 7: Training, $2 \mathrm{~Hz}, 5 \mathrm{~mm}$ ) were similar

669 in shape to previous representative traces for the rat soleus (Swoap et al., 1997).

670

Net work output decreased with increasing cycle frequency and on either side of the

671 optimal strain. At shorter strains, there is mathematically lower mechanical work, as work is the

672 product of force and length change. At longer strains, the muscle undergoes greater stretch,

673 thereby increasing passive force development in addition to active force development, and

674 bringing the work of lengthening closer to or above work of shortening (Josephson, 1999; Swoap

675 et al., 1997). Since work of shortening decreased with increasing cycle frequency while work of

676 lengthening did not change, the decreased net work output with increasing cycle frequency can be

677 attributed to the force-velocity relationship (i.e., force decreases with increasing shortening 
678 velocity due to less opportunity for crossbridge formation (Alcazar et al., 2019; Josephson, 1999)).

679 Shorter muscle strain allows greater work at a faster cycle frequency because the shortening 680 velocity (length change / time) is mathematically slower (James et al., 1995; Josephson and Stokes, 681 1989). The ability to perform at faster cycle frequencies can also depend on sarcoplasmic 682 reticulum volume density (Lindstedt et al., 1998; Schaeffer and Lindstedt, 2013), and muscle fiber 683 type (Swoap et al., 1997). Since the rat soleus is primarily a slow-twitch muscle (Armstrong and 684 Phelps, 1984), it is understandable that net work output decreased considerably past a cycle 685 frequency as slow as $1.5 \mathrm{~Hz}$; this is consistent with previous work loops for the rat soleus (Caiozzo and Baldwin, 1997; Swoap et al., 1997).

One notable difference from Swoap et al. (1997) is they determined optimal strain for the rat soleus at $1.5 \mathrm{~Hz}$ to be $5 \mathrm{~mm}$, while in the present study it was 1 to $3 \mathrm{~mm}$. This may be because Swoap et al. (1997) tied the muscle at the distal end of the Achilles tendon, while we tied at the

690 musculotendinous junctions. Incorporating tendon into work loops can improve net work output 691 by adding forces generated by elastic recoil (Roberts, 2016), allowing muscle fibers to shorten at 692 closer to optimal speeds (Lichtwark and Barclay, 2010), and buffering muscle damage during stretch (Griffiths, 1991). Swoap et al. (1997) also used a higher temperature $\left(30^{\circ} \mathrm{C}\right.$ versus $\left.26^{\circ} \mathrm{C}\right)$,

694 which can enhance force production in higher velocity/length change combinations (Ranatunga, 695 2018; Roots and Ranatunga, 2008). Altogether, while not perfect, our work loops still provide 696 insight into how the rat soleus functions during cyclic contractions of various speeds and strains. 
701 was partly correct. An effect of group showed that trained rats produced overall greater net work

702 output in the active work loops, with the most pronounced increases occurring in the $1.5-\mathrm{Hz}$ loops

703 at 1, 3, and $5 \mathrm{~mm}$ (Figure 8C). These improvements in net work seemed to be due to increases in

704 work of shortening (i.e., active force during shortening) rather than decreases in work of

705 lengthening (Figure 8A and B). Our hypothesis may only stand if optimal SL remained the same

706 between control and trained rats. With increased SSN but the same SL, sarcomeres would stay in

707 closer range to optimal SL, and shortening velocity of individual sarcomeres would be reduced for

708 a given muscle excursion, improving active force production and thereby the mechanical work

709 (Baxter et al., 2018; Drazan et al., 2019). We observed a 4-5\% increase in optimal SL with

710 training, so it is possible the sarcomere shortening velocities and operating ranges with respect to

711 optimal SL did not change.

As shown in Table 1, we estimated the sarcomere operating ranges and shortening

713 velocities in the $1.5-\mathrm{Hz}$ work loops at strains of 1,3 , and $5 \mathrm{~mm}$ in trained and control rats. To do

714 this, we first determined the fraction of the measured FLs compared to the whole-muscle Lo's

715 (trained $=0.68$, control $=0.63$ ). By doing this, we can estimate what FL would be at a given

716 muscle length with respect to $\mathrm{L}_{\mathrm{O}}$ (e.g., in trained rats for a 3-mm strain: $\mathrm{L}_{\mathrm{O}}+1.5 \mathrm{~mm}=25.72 \mathrm{~mm}$

$717+1.5 \mathrm{~mm}=27.22 \mathrm{~mm} ; \mathrm{FL}=27.22 \mathrm{~mm} \times 0.68=18.51 \mathrm{~mm} ; \mathrm{Lo}_{\mathrm{o}}-1.5 \mathrm{~mm}=25.72 \mathrm{~mm}-1.5 \mathrm{~mm}$

$718=24.22 \mathrm{~mm} ; \mathrm{FL}=24.22 \mathrm{~mm} \times 0.68=16.47 \mathrm{~mm})$. Subsequently, we can estimate the SL at that

719 muscle length by dividing FL by the SSN (e.g., at $\mathrm{L}_{\mathrm{O}}+1.5 \mathrm{~mm}, 18.51 \mathrm{~mm} / 6024=3.07 \mu \mathrm{m}$; at

$\left.720 \mathrm{~L}_{\mathrm{O}}-1.5 \mathrm{~mm}, 16.47 \mathrm{~mm} / 6024=2.73 \mu \mathrm{m}\right)$. Assuming the width of the sarcomere force-length

721 relationship changed proportionately to SL, we can calculate the percentage that SL deviated from

722 optimal SL during the whole-muscle excursion (e.g. $[\{3.07-2.93\} / 2.93] \times 100 \%= \pm 4.78 \%)$.

723 We can also estimate the sarcomere shortening velocity in an excursion by multiplying the 
sarcomere displacement by 2 times the cycle frequency (e.g., $[3.07 \mu \mathrm{m}-2.73 \mu \mathrm{m}] \times(1.5 \mathrm{~Hz} \times 2)$

$=1.02 \mu \mathrm{m} / \mathrm{s}$ ). Because optimal SL is different between groups, these velocities should also be

expressed as SL/s for comparisons (e.g., $1.02 \mu \mathrm{m} / \mathrm{s} / 2.93 \mu \mathrm{m}=0.11 \mathrm{SL} / \mathrm{s}$ ).

727

Table 1: Estimated sarcomere operating ranges and shortening velocities in the work loops that

729 improved with training

\begin{tabular}{|c|c|c|c|c|c|c|}
\hline & \multicolumn{3}{|c|}{$\begin{array}{l}\text { Control (measured resting length at Lo: } 2.81 \\
\mu \mathrm{m})\end{array}$} & \multicolumn{3}{|c|}{$\begin{array}{l}\text { Trained (measured resting length at Lo: } 2.93 \\
\mu \mathrm{m})\end{array}$} \\
\hline Strain & $\begin{array}{l}\mathrm{SL} \\
\text { range }\end{array}$ & $\begin{array}{l}\text { Excursion from } \\
\text { optimal SL }\end{array}$ & $\begin{array}{l}\text { Shortening } \\
\text { velocity at } 1.5 \mathrm{~Hz}\end{array}$ & $\begin{array}{l}\mathrm{SL} \\
\text { range }\end{array}$ & $\begin{array}{l}\text { Excursion from } \\
\text { optimal SL }\end{array}$ & $\begin{array}{l}\text { Shortening } \\
\text { velocity at } 1.5 \mathrm{~Hz}\end{array}$ \\
\hline $1 \mathrm{~mm}$ & $\begin{array}{l}2.73- \\
2.85 \mu \mathrm{m}\end{array}$ & $\pm 1.42 \%$ & $0.13 \mathrm{SL} / \mathrm{s}$ & $\begin{array}{l}2.85- \\
2.96 \mu \mathrm{m}\end{array}$ & $\pm 1.02 \%$ & $0.11 \mathrm{SL} / \mathrm{s}$ \\
\hline $3 \mathrm{~mm}$ & $\begin{array}{l}2.62- \\
2.96 \mu \mathrm{m}\end{array}$ & $\pm 5.34 \%$ & $0.36 \mathrm{SL} / \mathrm{s}$ & $\begin{array}{l}2.73- \\
3.07 \mu \mathrm{m}\end{array}$ & $\pm 4.78 \%$ & $0.35 \mathrm{SL} / \mathrm{s}$ \\
\hline $5 \mathrm{~mm}$ & $\begin{array}{l}2.51- \\
3.07 \mu \mathrm{m}\end{array}$ & $\pm 9.25 \%$ & $0.66 \mathrm{SL} / \mathrm{s}$ & $\begin{array}{l}2.62- \\
3.19 \mu \mathrm{m}\end{array}$ & $\pm 8.87 \%$ & $0.58 \mathrm{SL} / \mathrm{s}$ \\
\hline
\end{tabular}

Lo: optimal muscle length; SL: sarcomere length

From the estimations in Table 1, it appears that the sarcomeres of trained rats indeed 
743 performance, at least at the 1 and 3-mm strains, but FL and SL adaptations were more important

744 for improved net work output at the 3 and 5-mm strains (Figure 9).

To our knowledge, one other study on animals has assessed the impact of sarcomerogenesis on work loop performance (Cox et al., 2000). After incrementally surgically stretching the rabbit latissimus dorsi for 3 weeks, they observed a $25 \%$ increase in SSN compared to controls, however, maximum work loop power output decreased by $40 \%$, and the optimal cycle frequency shifted this detriment to work loop performance was related to energy loss (i.e., more negative work in 751 passive work loops) caused by collagen accumulation, because after an additional 3 weeks of 752 maintained stretch, collagen content decreased back toward control values, SSN increased another

$7535 \%$, and work loop power output returned to normal. As the present study observed no changes in

754 collagen content or crosslinking per unit volume of muscle, we were able to demonstrate 755 improvements in work loop performance alongside sarcomerogenesis in the absence of 756 intramuscular collagen accumulation.

Some studies on humans have also connected increased FL to improved mechanical work or power output. In the ankle plantar flexors, Beck et al. (2021, preprint) observed lower metabolic costs of cyclic force production in longer compared to shorter fascicle operating lengths under the

760 same mechanical work and shortening velocity. Hinks et al. (2020) and Davidson et al. (2022)

761 observed a 4\% increase in tibialis anterior FL following 8 weeks of isometric training at a long 762 muscle-tendon unit length, and an $11 \%$ increase in work of shortening, and $25 \%$ and $33 \%$ increases 763 in isotonic power at loads of $10 \%$ and $50 \%$ maximum, respectively. However, they also observed 764 increased isometric strength, pennation angle, and muscle thickness, so we can only speculate that 765 those improvements in work and power were due to increased FL rather than strength and 
766 hypertrophy. Lastly, a computational model by Drazan et al. (2019) showed longer medial

767 gastrocnemius fascicles produce greater force throughout the range of motion, increasing work of

768 shortening. Further work in animals is required to elucidate whether increased FL and SSN, with

769 constant SL, can improve net work output in cyclic contractions.

\section{Conclusion}

772 The purpose of this study was to assess muscle architecture and work loop performance of

773 the rat soleus following 4 weeks of progressively loaded weighted downhill running training.

774 Aligning with our hypotheses, longitudinal muscle growth occurred, with a 13\% increase in FL

775 which appeared to stem from an $8 \%$ increase in SSN and a 4-5\% increase in optimal SL. This

776 longitudinal muscle growth corresponded to rightward shifts in the active and passive force-length

777 relationships. Work loop performance improved most in the slowest cycle frequency at the 3

778 shortest strains. Based on regression analyses and mathematical estimations, it is feasible that

779 these improvements in work loop performance were due to the observed longitudinal muscle

780 growth, alongside (and to a lesser extent) improvements in force generating capacity independent

781 of PCSA. Future research should assess the time course of SL and SSN adaptations with training,

782 and the accompanying influence on dynamic contractile function. 


\section{Acknowledgements}

785 This project was supported by the Natural Sciences and Engineering Research Council of Canada (NSERC) and the Canadian Institutes of Health Research (CIHR). Infrastructure was provided by the University of Guelph start-up funding. No conflicts of interest, financial or otherwise, are declared by the authors.

\section{Disclosure statement}

791 No conflicts of interest, financial or otherwise, are declared by the authors.

\section{Ethics statement}

All procedures were approved by the Animal Care Committee of the University of Guelph.

\section{Data accessibility}

Individual values of all supporting data are available upon request.

Grants

800 This project was supported by the Natural Sciences and Engineering Research Council of Canada 801 (NSERC) and the Canadian Institutes of Health Research (CIHR). Infrastructure was provided by 802 the University of Guelph start-up funding.

803

\section{Author contributions}

805 A.H., K.D.M, D.C.W, S.H.M.B., and G.A.P. conceived and designed research; A.H., K.J., and 806 P.M. carried out animal husbandry and training; A.H. performed experiments; A.H. and K.J. 807 analyzed data; A.H., M.V.F., S.H.M.B., and G.A.P. interpreted results of experiments; A.H. 808 prepared figures; A.H. and G.A.P. drafted manuscript; A.H., K.J., P.M., K.D.M., M.V.F., D.C.W., 809 S.H.M.B., and G.A.P. edited and revised manuscript; A.H., K.J., P.M., K.D.M., M.V.F., D.C.W., 


\section{References}

Akagi, R., Hinks, A. and Power, G. A. (2020). Differential changes in muscle architecture and neuromuscular fatigability induced by isometric resistance training at short and long muscle-tendon unit lengths. J. Appl. Physiol. 129, 173-184.

Alcazar, J., Csapo, R., Ara, I. and Alegre, L. M. (2019). On the Shape of the Force-Velocity Relationship in Skeletal Muscles: The Linear, the Hyperbolic, and the DoubleHyperbolic. Front. Physiol. 10, 769.

Alder, A. B., Crawford, G. N. C. and Edwards, R. G. (1958). The growth of the muscle tibialis anterior in the normal rabbit in relation to the tension-length ratio. Proc. R. Soc. Lond. Ser. B - Biol. Sci. 148, 207-216.

Aoki, M. S., Soares, A. G., Miyabara, E. H., Baptista, I. L. and Moriscot, A. S. (2009). Expression of genes related to myostatin signaling during rat skeletal muscle longitudinal growth: Myostatin and Longitudinal Growth. Muscle Nerve 40, 992-999.

Armstrong, R. B. and Phelps, R. O. (1984). Muscle fiber type composition of the rat hindlimb. Am. J. Anat. 171, 259-272.

Baker, J. H. and Hall-Craggs, E. C. B. (1978). Changes in length of sarcomeres following tenotomy of the rat soleus muscle. Anat. Rec. 192, 55-58.

Baxter, J. R., Hullfish, T. J. and Chao, W. (2018). Functional deficits may be explained by plantarflexor remodeling following Achilles tendon rupture repair: Preliminary findings. J. Biomech. 79, 238-242.

Beck, O. N., Schroeder, J. N., Trejo., L. H., Franz, J. R. and Sawicki, G. S. (2021). Relatively Shorter Muscle Lengths Increase the Metabolic Rate of Cyclic Force Production. bioRXiv.

Bogomolovas, J., Fleming, J. R., Franke, B., Manso, B., Simon, B., Gasch, A., Markovic, M., Brunner, T., Knöll, R., Chen, J., et al. (2021). Titin kinase ubiquitination aligns autophagy receptors with mechanical signals in the sarcomere. EMBO Rep. 22,.

Brashear, S. E., Wohlgemuth, R. P., Gonzalez, G. and Smith, L. R. (2020). Passive stiffness of fibrotic skeletal muscle in $\mathrm{mdx}$ mice relates to collagen architecture. J. Physiol. Online ahead of print.

Butterfield, T. A. and Herzog, W. (2006). The magnitude of muscle strain does not influence serial sarcomere number adaptations following eccentric exercise. Pflüg. Arch. - Eur. J. Physiol. 451, 688-700.

Butterfield, T. A., Leonard, T. R. and Herzog, W. (2005a). Differential serial sarcomere number adaptations in knee extensor muscles of rats is contraction type dependent. $J \mathrm{Appl}$ Physiol 99, 7. 
Butterfield, T. A., Leonard, T. R. and Herzog, W. (2005b). Differential serial sarcomere number adaptations in knee extensor muscles of rats is contraction type dependent. $J$. Appl. Physiol. 99, 1352-1358.

Caiozzo, V. J. and Baldwin, K. M. (1997). Determinants of work produced by skeletal muscle: potential limitations of activation and relaxation. Am. J. Physiol.-Cell Physiol. 273, C1049-C1056.

Chen, J., Mashouri, P., Fontyn, S., Valvano, M., Elliott-Mohamed, S., Noonan, A. M., Brown, S. H. M. and Power, G. A. (2020). The influence of training-induced sarcomerogenesis on the history dependence of force. J. Exp. Biol. 223, jeb218776.

Coutinho, E. L., Gomes, A. R. S., França, C. N., Oishi, J. and Salvini, T. F. (2004). Effect of passive stretching on the immobilized soleus muscle fiber morphology. Braz. J. Med. Biol. Res. 37, 1853-1861.

Cox, V. M., Williams, P. E., Wright, H., James, R. S., Gillott, K. L., Young, I. S. and Goldspink, D. F. (2000). Growth induced by incremental static stretch in adult rabbit latissimus dorsi muscle. Exp Physiol 85, 193-202.

Davidson, B., Hinks, A., Dalton, B. H., Akagi, R. and Power, G. A. (2022). Power attenuation from restricting range of motion is minimized in subjects with fast RTD and following isometric training. J. Appl. Physiol. 132, 497-510.

Davis, J. F., Khir, A. W., Barber, L., Reeves, N. D., Khan, T., DeLuca, M. and Mohagheghi, A. A. (2020). The mechanisms of adaptation for muscle fascicle length changes with exercise: Implications for spastic muscle. Med. Hypotheses 144, 110199.

De Jaeger, D., Joumaa, V. and Herzog, W. (2015). Intermittent stretch training of rabbit plantarflexor muscles increases soleus mass and serial sarcomere number. J. Appl. Physiol. 118, 1467-1473.

De Koning, J. J., Van Der Molen, H. F., Woittiez, R. D. and Huijing, P. A. (1987). Functional characteristics of rat gastrocnemius and tibialis anterior muscles during growth. J. Morphol. 194, 75-84.

Drazan, J. F., Hullfish, T. J. and Baxter, J. R. (2019). Muscle structure governs joint function: linking natural variation in medial gastrocnemius structure with isokinetic plantar flexor function. Biol. Open bio. 048520.

Farup, J., Kjølhede, T., Sørensen, H., Dalgas, U., Møller, A. B., Vestergaard, P. F., Ringgaard, S., Bojsen-Møller, J. and Vissing, K. (2012). Muscle Morphological and Strength Adaptations to Endurance Vs. Resistance Training. J. Strength Cond. Res. 26, 398-407.

Fitts, R. H., McDonald, K. S. and Schluter, J. M. (1991). The determinants of skeletal muscle force and power: Their adaptability with changes in activity pattern. J. Biomech. 24, 111122. 
Franchi, M. V., Ruoss, S., Valdivieso, P., Mitchell, K. W., Smith, K., Atherton, P. J., Narici, M. V. and Flück, M. (2018). Regional regulation of focal adhesion kinase after concentric and eccentric loading is related to remodelling of human skeletal muscle. Acta Physiol. 223, e13056.

Gans, C. and Bock, W. J. (1965). The functional significance of muscle architecture--a theoretical analysis. Ergeb Anat Entwicklungsgesch 38, 115-42.

Gans, C. and de Vree, F. (1987). Functional bases of fiber length and angulation in muscle. $J$. Morphol. 192, 63-85.

Gillies, A. R. and Lieber, R. L. (2011). Structure and function of the skeletal muscle extracellular matrix: Skeletal Muscle ECM. Muscle Nerve 44, 318-331.

Gokhin, D. S., Dubuc, E. A., Lian, K. Q., Peters, L. L. and Fowler, V. M. (2014). Alterations in thin filament length during postnatal skeletal muscle development and aging in mice. Front. Physiol. 5,

Gordon, A. M., Huxley, A. F. and Julian, F. J. (1966a). The variation in isometric tension with sarcomere length in vertebrate muscle fibres. J. Physiol. 184, 170-192.

Gordon, A. M., Huxley, A. F. and Julian, F. J. (1966b). Tension development in highly stretched vertebrate muscle fibres. J. Physiol. 184, 143-169.

Griffiths, R. I. (1991). Shortening of muscle fibres during stretch of the active cat medial gastrocnemius muscle: the role of tendon compliance. J. Physiol. 436, 219-236.

Han, X.-Y., Wang, W., Koskinen, S. O. A., Kovanen, V., Takala, T. E. S., Komulainen, J., Vihko, V. and Trackman, P. C. (1999). Increased mRNAs for procollagens and key regulating enzymes in rat skeletal muscle following downhill running. Pflüg. Arch. Eur. J. Physiol. 437, 857-864.

Haun, C. T., Vann, C. G., Roberts, B. M., Vigotsky, A. D., Schoenfeld, B. J. and Roberts, M. D. (2019). A Critical Evaluation of the Biological Construct Skeletal Muscle Hypertrophy: Size Matters but So Does the Measurement. Front. Physiol. 10, 247.

Heinemeier, K. M., Olesen, J. L., Haddad, F., Langberg, H., Kjaer, M., Baldwin, K. M. and Schjerling, P. (2007). Expression of collagen and related growth factors in rat tendon and skeletal muscle in response to specific contraction types: Collagen and TGF- $\beta-1$ expression in exercised tendon and muscle. J. Physiol. 582, 1303-1316.

Herbert, R. D. and Balnave, R. J. (1993). The effect of position of immobilisation on resting length, resting stiffness, and weight of the soleus muscle of the rabbit. J. Orthop. Res. 11, 358-366.

Herbert, R. D. and Gandevia, S. C. (2019). The passive mechanical properties of muscle. $J$. Appl. Physiol. 126, 1442-1444. 
Herring, S. W., Grimm, A. F. and Grimm, B. R. (1984). Regulation of sarcomere number in skeletal muscle: A comparison of hypotheses. Muscle Nerve 7, 161-173.

Herzog, W. and Fontana, H. de B. (2021). Does eccentric exercise stimulate sarcomerogenesis? J. Sport Health Sci. S2095254621001083.

Heslinga, J. W. and Huijing, P. A. (1993). Muscle length-force characteristics in relation to muscle architecture: a bilateral study of gastrocnemius medialis muscles of unilaterally immobilized rats. Eur. J. Appl. Physiol. 66, 289-298.

Hinks, A., Davidson, B., Akagi, R. and Power, G. A. (2021). Influence of isometric training at short and long muscle-tendon unit lengths on the history dependence of force. Scand. J. Med. Sci. Sports 31, 325-338.

Honda, Y., Tanaka, M., Tanaka, N., Sasabe, R., Goto, K., Kataoka, H., Sakamoto, J., Nakano, J. and Okita, M. (2018). Relationship between extensibility and collagen expression in immobilized rat skeletal muscle. Muscle Nerve 57, 672-678.

Huijing, P. A. (1999). Muscle as a collagen fiber reinforced composite: a review of force transmission in muscle and whole limb. J. Biomech. 32, 329-345.

Hyldahl, R. D. and Hubal, M. J. (2014). Lengthening our perspective: Morphological, cellular, and molecular responses to eccentric exercise: Exercise-Induced Muscle Damage. Muscle Nerve 49, 155-170.

Jahromi, S. S. and Charlton, M. P. (1979). Transverse sarcomere splitting. A possible means of longitudinal growth in crab muscles. J. Cell Biol. 80, 736-742.

Jakubiec-Puka, A. and Carraro, U. (1991). Remodelling of the contractile apparatus of striated muscle stimulated electrically in a shortened position. J. Anat. 178, 83-100.

James, R. S., Altringham, J. D. and Goldspink, D. F. (1995). THE MECHANICAL PROPERTIES OF FAST AND SLOW SKELETAL MUSCLES OF THE MOUSE IN RELATION TO THEIR LOCOMOTORY FUNCTION. J. Exp. Biol. 198, 491-502.

Jorgenson, K. W., Phillips, S. M. and Hornberger, T. A. (2020). Identifying the Structural Adaptations that Drive the Mechanical Load-Induced Growth of Skeletal Muscle: A Scoping Review. Cells 9, 1658.

Josephson, R. K. (1999). Dissecting muscle power output. J. Exp. Biol. 202, 3369-3375.

Josephson, R. K. and Stokes, D. R. (1989). STRAIN,MUSCLE LENGTH ANDWORK OUTPUT IN A CRAB MUSCLE. J. Exp. Biol. 145, 45-61.

Karpakka, J. A., Pesola, M. K. and Takala Timo E. S. (1992). Thee effects of anabolic steroids on collagen synthesis in rat skeletal muscle and tendon. Am. J. Sports Med. 20, $262-266$. 
Kjær, M. (2004). Role of Extracellular Matrix in Adaptation of Tendon and Skeletal Muscle to Mechanical Loading. Physiol. Rev. 84, 649-698.

Koh, T. J. (1995). Do adaptations in serial sarcomere number occur with strength training? Hum. Mov. Sci. 14, 61-77.

Koh, T. J. and Tidball, J. G. (1999). Nitric oxide synthase inhibitors reduce sarcomere addition in rat skeletal muscle. J. Physiol. 519, 189-196.

Lichtwark, G. A. and Barclay, C. J. (2010). The influence of tendon compliance on muscle power output and efficiency during cyclic contractions. J. Exp. Biol. 213, 707-714.

Lieber, R. L. and Ward, S. R. (2011). Skeletal muscle design to meet functional demands. Philos. Trans. R. Soc. B Biol. Sci. 366, 1466-1476.

Lieber, R. L., Yeh, Y. and Baskin, R. J. (1984). Sarcomere length determination using laser diffraction. Effect of beam and fiber diameter. Biophys. J. 45, 1007-1016.

Lindstedt, S. L., McGlothlin, T., Percy, E. and Pifer, J. (1998). Task-specific design of skeletal muscle: balancing muscle structural composition. Comp. Biochem. Physiol. B Biochem. Mol. Biol. 120, 35-40.

Lochyński, D., Kaczmarek, D., Grześkowiak, M., Majerczak, J., Podgórski, T. and Celichowski, J. (2021). Motor Unit Force Potentiation and Calcium Handling Protein Concentration in Rat Fast Muscle After Resistance Training. Front. Physiol. 12, 652299.

Lutz, G. J. and Rome, L. C. (1994). Built for Jumping: The Design of the Frog Muscular System. Sci. New Ser. 263, 370-372.

Lynn, R., Talbot, J. A. and Morgan, D. L. (1998). Differences in rat skeletal muscles after incline and decline running. J. Appl. Physiol. 85, 98-104.

Macadam, P., Cronin, J. B. and Feser, E. H. (2019). Acute and longitudinal effects of weighted vest training on sprint-running performance: a systematic review. Sports Biomech. 1-16.

Morais, G. P., da Rocha, A. L., Neave, L. M., de A. Lucas, G., Leonard, T. R., Carvalho, A., da Silva, A. S. R. and Herzog, W. (2020). Chronic uphill and downhill exercise protocols do not lead to sarcomerogenesis in mouse skeletal muscle. J. Biomech. 98, 109469.

Narici, M., Franchi, M. and Maganaris, C. (2016). Muscle structural assembly and functional consequences. J. Exp. Biol. 219, 276-284.

Nicolopoulos-Stournaras, S. and Iles, J. F. (1983). Hindlimb muscle activity during locomotion in the rat (Rattus norvegicus) (Rodentia: Muridae). J. Zool. 203, 427-440. 
Noonan, A. M., Mashouri, P., Chen, J., Power, G. A. and Brown, S. H. M. (2020). Training Induced Changes to Skeletal Muscle Passive Properties Are Evident in Both Single Fibers and Fiber Bundles in the Rat Hindlimb. Front. Physiol. 11, 907.

Ochi, E., Nakazato, K. and Ishii, N. (2007). Effects of Eccentric Exercise on Joint Stiffness and Muscle Connectin (Titin) Isoform in the Rat Hindlimb. J. Physiol. Sci. 57, 1-6.

Ranatunga, K. (2018). Temperature Effects on Force and Actin-Myosin Interaction in Muscle: A Look Back on Some Experimental Findings. Int. J. Mol. Sci. 19, 1538.

Roberts, T. J. (2016). Contribution of elastic tissues to the mechanics and energetics of muscle function during movement. J. Exp. Biol. 219, 266-275.

Rome, L. C. (1994). The mechanical design of the fish muscular system. Mech. Physiol. Anim. Swim. 75-98.

Roots, H. and Ranatunga, K. W. (2008). An analysis of the temperature dependence of force, during steady shortening at different velocities, in (mammalian) fast muscle fibres. $J$. Muscle Res. Cell Motil. 29, 9-24.

Roy, R. R., Meadows, I. D., Baldwin, K. M. and Edgerton, V. R. (1982). Functional significance of compensatory overloaded rat fast muscle. J. Appl. Physiol. 52, 473-478.

Roy, R. R., Hutchison, D. L., Pierotti, D. J., Hodgson, J. A. and Edgerton, V. R. (1991). EMG patterns of rat ankle extensors and flexors during treadmill locomotion and swimming. J. Appl. Physiol. 70, 2522-2529.

Roy, R. R., Zhong, H., Monti, R. J., Vallance, K. A. and Edgerton, V. R. (2002). Mechanical properties of the electrically silent adult rat soleus muscle. Muscle Nerve 26, 404-412.

Salzano, M. Q., Cox, S. M., Piazza, S. J. and Rubenson, J. (2018). American Society of Biomechanics Journal of Biomechanics Award 2017: High-acceleration training during growth increases optimal muscle fascicle lengths in an avian bipedal model. J. Biomech. 80, $1-7$.

Schaeffer, P. J. and Lindstedt, S. L. (2013). How Animals Move: Comparative Lessons on Animal Locomotion. Compr. Physiol. 3, 289-314.

Schilder, R. J., Kimball, S. R., Marden, J. H. and Jefferson, L. S. (2011). Body weightdependent troponin $\mathrm{T}$ alternative splicing is evolutionarily conserved from insects to mammals and is partially impaired in skeletal muscle of obese rats. J. Exp. Biol. 214, $1523-1532$.

Shrager, J. B., Kim, D.-K., Hashmi, Y. J., Stedman, H. H., Zhu, J., Kaiser, L. R. and Levine, S. (2002). Sarcomeres Are Added in Series to Emphysematous Rat Diaphragm After Lung Volume Reduction Surgery. Chest 121, 210-215. 
Soares, A. G., Aoki, M. S., Miyabara, E. H., DeLuca, C. V., Ono, H. Y., Gomes, M. D. and Moriscot, A. S. (2007). Ubiquitin-ligase and deubiquitinating gene expression in stretched rat skeletal muscle. Muscle Nerve 36, 685-693.

1023

1024

1025

1026

1027

1028

1029

1030

1031

1032

1033

1034

1035

1036

1037

1038

1039

1040

1041

1042

1043

1044

1045

1046

1047

1048

1049

1050

1051

1052

1053

1054

1055

Spletter, M. L., Barz, C., Yeroslaviz, A., Zhang, X., Lemke, S. B., Bonnard, A., Brunner, E., Cardone, G., Basler, K., Habermann, B. H., et al. (2018). A transcriptomics resource reveals a transcriptional transition during ordered sarcomere morphogenesis in flight muscle. eLife 7, e34058.

Sugama, S., Tachino, K. and Haida, N. (1999). Effect of Immobilization on Solubility of Soleus and Gastrocnemius Muscle Collagen. Biochemical Studies on Collagen from Soleus and Gastrocnemius Muscles of Rat. J. Jpn. Phys. Ther. Assoc. 2, 25-29.

Swoap, S. J., Caiozzo, V. J. and Baldwin, K. M. (1997). Optimal shortening velocities for in situ power production of rat soleus and plantaris muscles. Am. J. Physiol.-Cell Physiol. 273, C1057-C1063.

Tabary, J. C., Tabary, C., Tardieu, C., Tardieu, G. and Goldspink, G. (1972). Physiological and structural changes in the cat's soleus muscle due to immobilization at different lengths by plaster casts*. J. Physiol. 224, 231-244.

Takahashi, M., Ward, S. R., Fridén, J. and Lieber, R. L. (2012). Muscle excursion does not correlate with increased serial sarcomere number after muscle adaptation to stretched tendon transfer: FUNCTIONAL ADAPTATION AFTER TENDON TRANSFER. $J$. Orthop. Res. 30, 1774-1780.

Turrina, A., Martínez-González, M. A. and Stecco, C. (2013). The muscular force transmission system: Role of the intramuscular connective tissue. J. Bodyw. Mov. Ther. 17, 95-102.

Walker, S. M. and Schrodt, G. R. (1974). I segment lengths and thin filament periods in skeletal muscle fibers of the rhesus monkey and the human. Anat. Rec. 178, 63-81.

Ward, S. R. and Lieber, R. L. (2005). Density and hydration of fresh and fixed human skeletal muscle. J. Biomech. 38, 2317-2320.

Wickiewicz, T. L., Roy, R. R., Powell, P. L., Perrine, J. J. and Edgerton, V. R. (1984). Muscle architecture and force-velocity relationships in humans. J. Appl. Physiol. 57, 435-443.

Widrick, J. J., Maddalozzo, G. F., Hu, H., Herron, J. C., Iwaniec, U. T. and Turner, R. T. (2008). Detrimental effects of reloading recovery on force, shortening velocity, and power of soleus muscles from hindlimb-unloaded rats. Am. J. Physiol.-Regul. Integr. Comp. Physiol. 295, R1585-R1592.

Williams, P. E. and Goldspink, G. (1973). The effect of immobilization on the longitudinal growth of striated muscle fibres. J. Anat. 116, 45-55. 
Williams, P. E. and Goldspink, G. (1978). Changes in sarcomere length and physiological properties in immobilized muscle. J. Anat. 127, 459-468.

Woittiez, R. D., Baan, G. C., Huijing, P. A. and Rozendal, R. H. (1985). Functional characteristics of the calf muscles of the rat. J. Morphol. 184, 375-387. growth. J. Morphol. 187, 247-258.

Wong, T. S. and Booth, F. W. (1988). Skeletal muscle enlargement with weight-lifting exercise by rats. J. Appl. Physiol. 65, 950-954.

Xu, H., Ren, X., Lamb, G. D. and Murphy, R. M. (2018). Physiological and biochemical characteristics of skeletal muscles in sedentary and active rats. J. Muscle Res. Cell Motil. 39, $1-16$.

Zhu, W. G., Hibbert, J. E., Lin, K.-H., Steinert, N. D., Lemens, J. L., Jorgenson, K. W., Newman, S. M., Lamming, D. W. and Hornberger, T. A. (2021). Weight Pulling: A Novel Mouse Model of Human Progressive Resistance Exercise. Cells 10, 2549. training alter collagen characteristics in fast- and slow-twitch rat limb muscle. J. Appl. Physiol. 75, 1670-1674.

1074 Zöllner, A. M., Abilez, O. J., Böl, M. and Kuhl, E. (2012). Stretching Skeletal Muscle: 
Body weight. Figure S1 shows body weight from the start of the training period to sacrifice. In control and trained rats, body weight increased up to 17 weeks of age (week 4 of training) (all comparisons $P<0.01$ ), then plateaued from 17 to 18 weeks of age (control: $P=0.74$, trained: $P=$ 0.09). While visually it appears that trained rats tended to weigh increasingly less than controls across the training period, there were no differences in body weight between trained and control rats at any weeks $(P=0.20-0.50)$. This observation strengthens comparability between the training and control groups, as it discounts differences in body weight as a confounding variable.

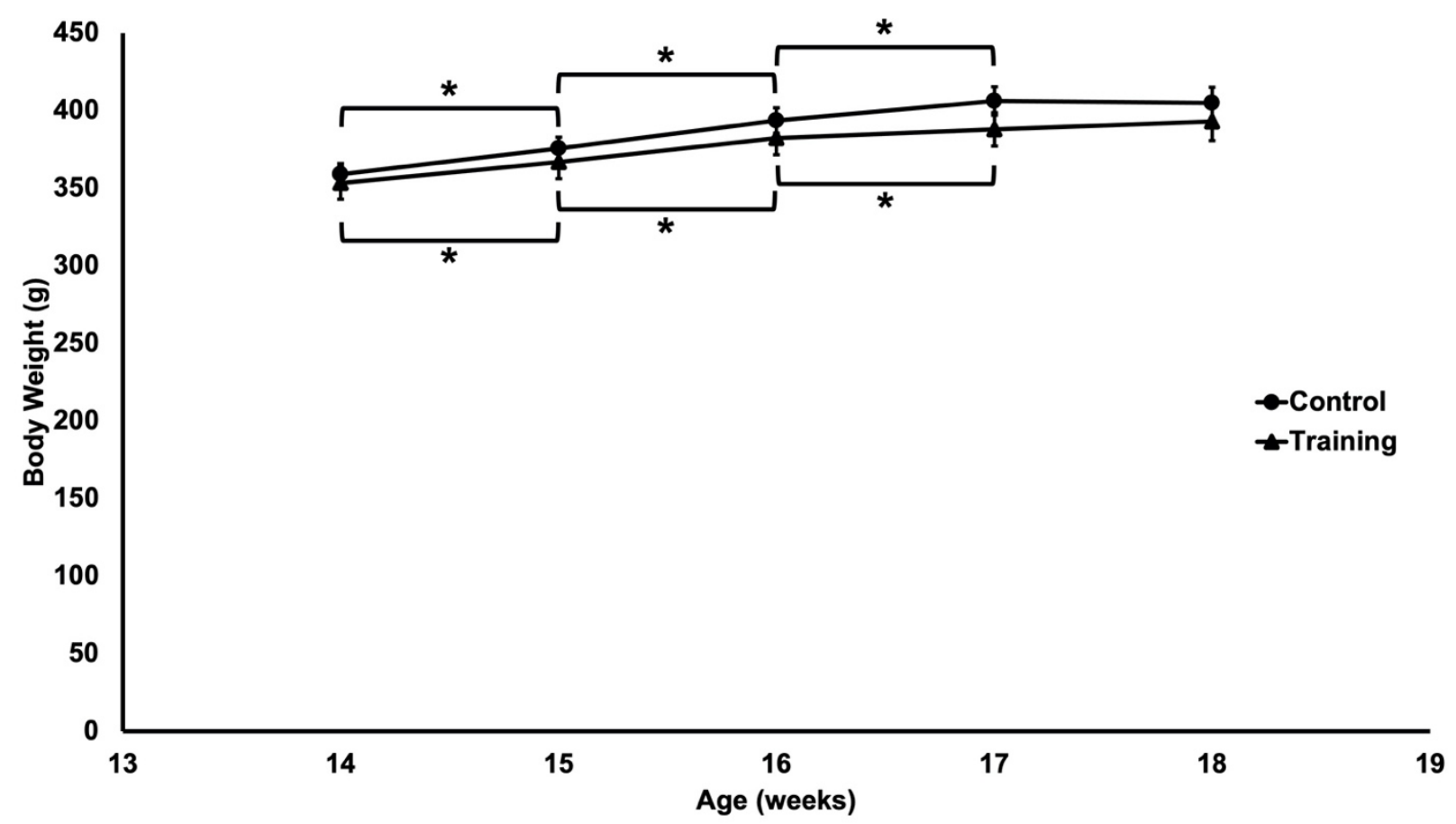

Figure S1: Changes in rat body weight from the start of the training period (age 14 weeks) to the day of sacrifice (age $\sim 18$ weeks) ( $\mathrm{n}=18$ control, $\mathrm{n}=14$ training). Data are reported as mean \pm standard error. *Significant difference between time points. 


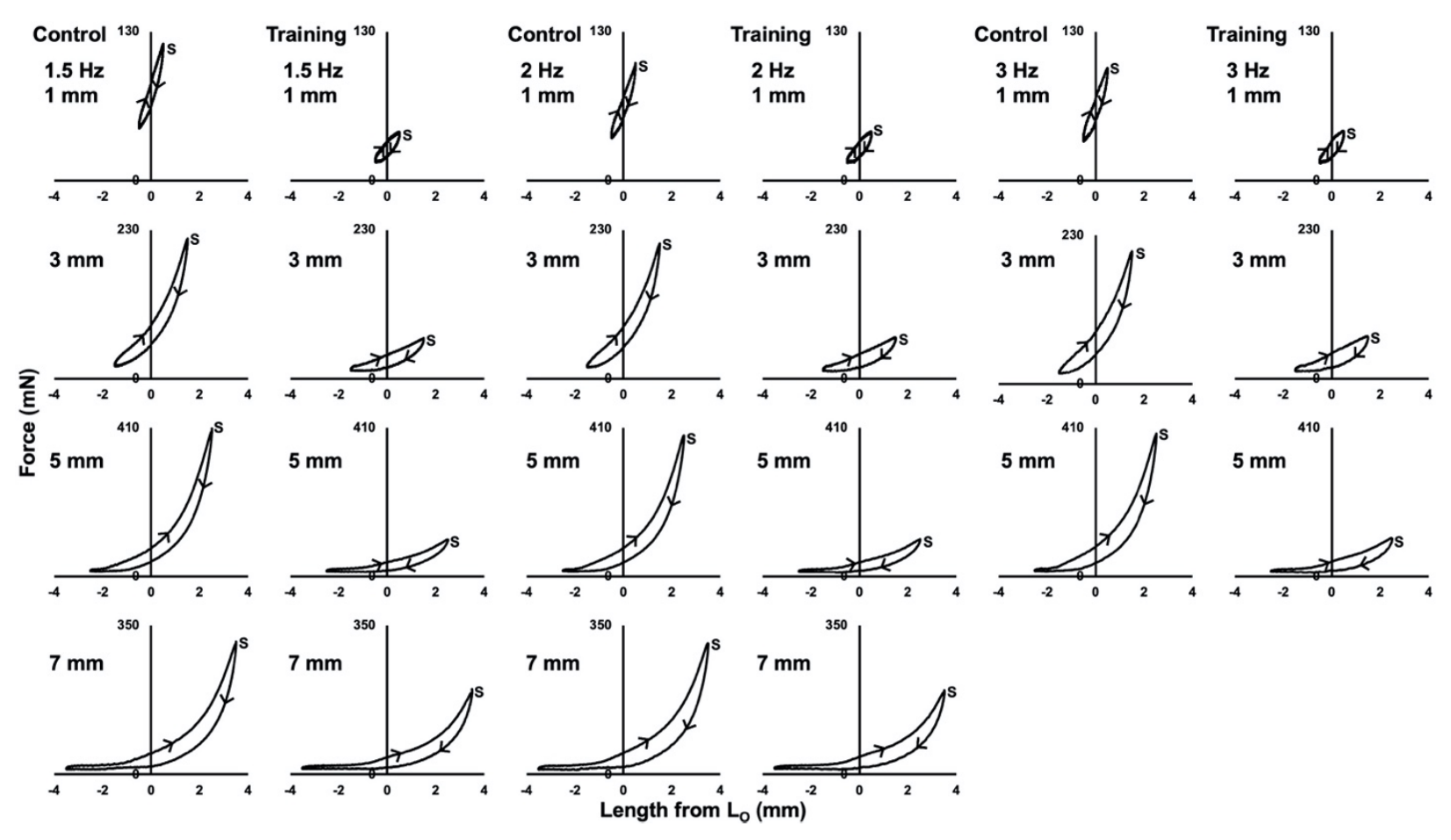

Figure S2: Representative passive (i.e., no stimulation) work loop traces for 1 control and 1 trained rat across cycle frequencies of $1.5,2$, and $3 \mathrm{~Hz}$, and strains of $1,3,5$, and $7 \mathrm{~mm}$. $S$ indicates the start of the cycle. Arrows indicate the direction of the cycle. 


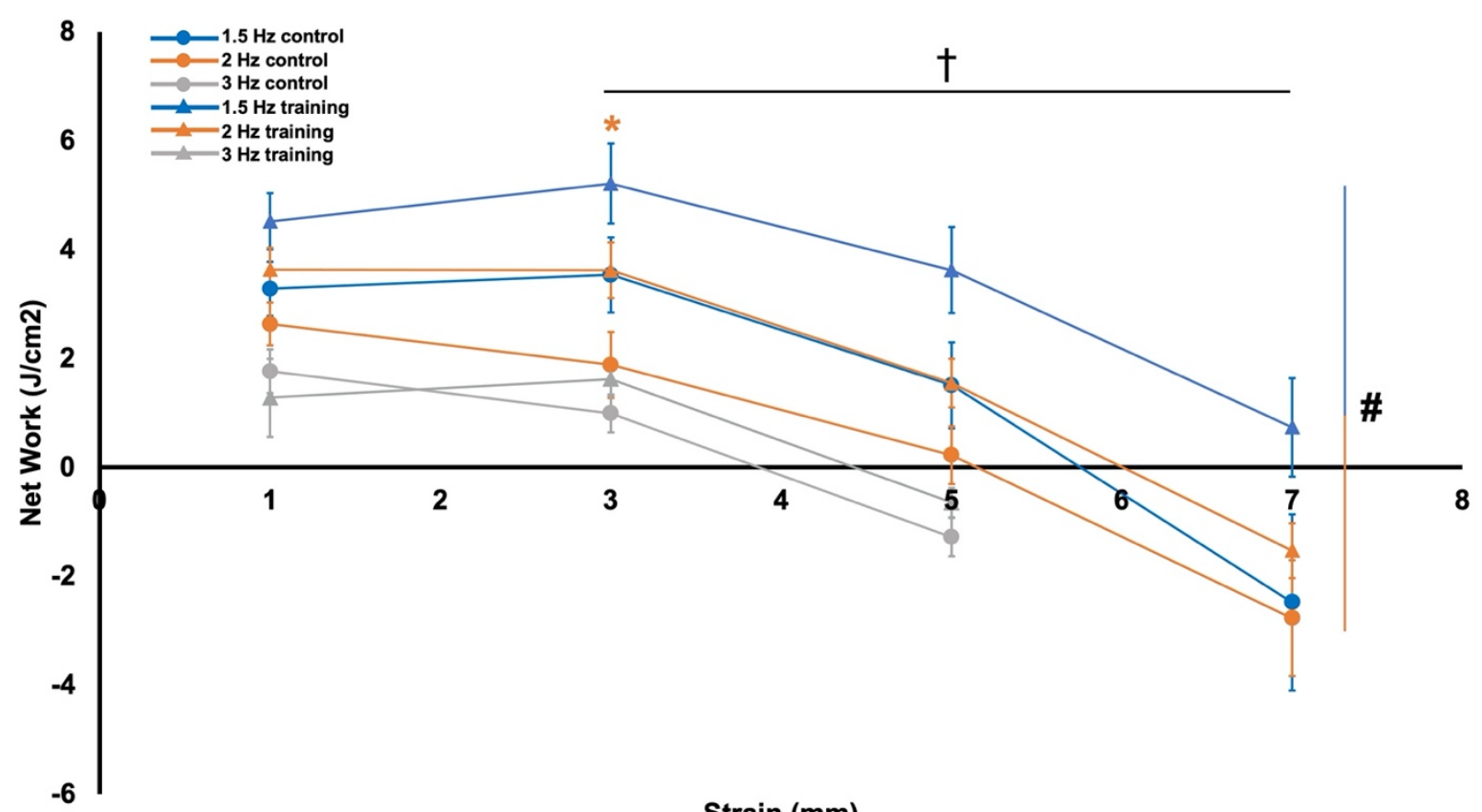

Strain $(\mathbf{m m})$

Figure S3: Estimated optimal net work output (i.e., work of shortening (positive) from the active work loops plus work of lengthening (negative) from the passive work loops) in control and trained rats. Data are reported as mean \pm standard error $(n=16$ control, $n=12$ training). *Significant difference $(P<0.05)$ between control and training at the colour-coded cycle frequency. \#Significant difference across cycle frequencies. †Significant difference across strains.

Across both groups, the estimated optimal net work output was greater than the measured (i.e., suboptimal) net work output in the $1.5-\mathrm{Hz}$ loops at 1,3 , and 5-mm strains, $2-\mathrm{Hz}$ loops at 1 , 3, 5, and 7-mm strains, and 3-Hz loops at 1, 3, and 5-mm strains (all $P<0.01$ ), but not the 1.5-Hz loop at a 7-mm strain $(P=0.19)$. Unlike in the measured work loops, estimated optimal net work output occurred on average in the $1.5-\mathrm{Hz}$ loop at a 3-mm strain in both trained and control rats. Like the suboptimal net work output, there was a group effect on estimated optimal net work output $\left(\mathrm{F}(1,304)=18.51, P<0.01, \eta_{\mathrm{p}}^{2}=0.06\right)$ with trained rats producing on average $1.30 \mathrm{~J} / \mathrm{cm}^{2}(95 \%$ 
CI $[0.73,1.88]$ more net work than controls across all work loops. There were no interactions of group $\times$ cycle frequency $\times$ strain $(F(5,304)=0.28, P=0.93)$, group $\times$ cycle frequency $(F(2,304)$ $=2.27, P=0.11)$, or group $\times$ strain $(\mathrm{F}(3,304)=0.68, P=0.56)$, suggesting differences between groups did not depend on cycle frequency or strain. Post-hoc tests indicated specifically estimated optimal net work output was 92\% greater in trained than control rats in in the 2-Hz, 3-mm work loop $(\mathrm{F}(1,26)=4.35, P<0.05, d=0.83)$ (Figure S3).

For estimated optimal net work output, there was an effect of cycle frequency $(F(2,304)=$ 30.56, $\left.P<0.01, \eta_{\mathrm{p}}^{2}=0.18\right)$, and strain $\left(\mathrm{F}(2,304)=52.13, P<0.01, \eta_{\mathrm{p}}{ }^{2}=0.36\right)$. Specifically, estimated optimal net work output also decreased with increasing cycle frequency expect for between 2 and $3 \mathrm{~Hz}(P=0.40$; all other comparisons $P<0.01)$, and increased with strain except for between 1 and $3 \mathrm{~mm}(P=1.00$; all other comparisons $P<0.01)$ (Figure S3). 